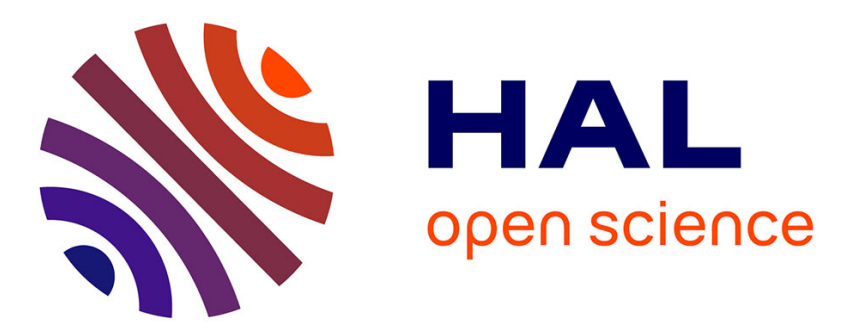

\title{
The relevance of aerosol optical depth to cumulus fraction changes: a five-year climatology at the ACRF SGP site
}

\author{
E. I. Kassianov, L. K. Berg, C. Flynn, S. Mcfarlane
}

\section{- To cite this version:}

E. I. Kassianov, L. K. Berg, C. Flynn, S. Mcfarlane. The relevance of aerosol optical depth to cumulus fraction changes: a five-year climatology at the ACRF SGP site. Atmospheric Chemistry and Physics Discussions, 2007, 7 (4), pp.11797-11837. hal-00303047

\section{HAL Id: hal-00303047 https://hal.science/hal-00303047}

Submitted on 13 Aug 2007

HAL is a multi-disciplinary open access archive for the deposit and dissemination of scientific research documents, whether they are published or not. The documents may come from teaching and research institutions in France or abroad, or from public or private research centers.
L'archive ouverte pluridisciplinaire HAL, est destinée au dépôt et à la diffusion de documents scientifiques de niveau recherche, publiés ou non, émanant des établissements d'enseignement et de recherche français ou étrangers, des laboratoires publics ou privés. 
Atmos. Chem. Phys. Discuss., 7, 11797-11837, 2007 www.atmos-chem-phys-discuss.net/7/11797/2007/

(c) Author(s) 2007. This work is licensed under a Creative Commons License.
Atmospheric

Chemistry and Physics Discussions

\section{The relevance of aerosol optical depth to cumulus fraction changes: a five-year climatology at the ACRF SGP site}

\section{E. I. Kassianov, L. K. Berg, C. Flynn, and S. McFarlane}

Pacific Northwest National Laboratory, 320 Q. Avenue, MSIN: K9-24, Richland, WA, 99352, USA

Received: 15 June 2007 - Accepted: 6 August 2007 - Published: 13 August 2007

Correspondence to: E. I. Kassianov (evgueni.kassianov@pnl.gov)

Relationships between aerosol optical depth and cumulus fraction

E. I. Kassianov et al.

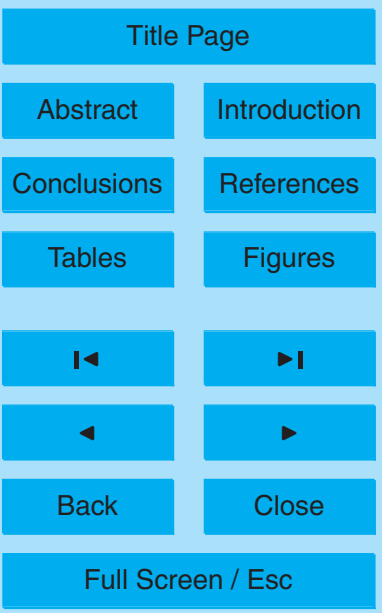

Printer-friendly Version

Interactive Discussion 


\section{Abstract}

The objective of this study is to investigate, by observational means, the magnitude and sign of the actively discussed relationship between cloud fraction $N$ and aerosol optical depth $\tau_{a}$. Collocated and coincident ground-based measurements and Terra/Aqua 5 satellite observations at the Atmospheric Radiation Measurement (ARM) Climate Research Facility (ACRF) Southern Great Plains (SGP) site form the basis of this study. The $N-\tau_{a}$ relationship occurred in a specific 5-year dataset of fair-weather cumulus (FWC) clouds and mostly non-absorbing aerosols. To reduce possible contamination of the aerosols on the cloud properties estimation (and vice versa), we use independent datasets of $\tau_{a}$ and $N$ obtained from the Multi-filter Rotating Shadowband Radiometer (MFRSR) measurements and from the ARM Active Remotely Sensed Clouds Locations (ARSCL) value-added product, respectively. Optical depth of the FWC clouds $\tau_{\text {cld }}$ and effective radius of cloud droplets $r_{e}$ are obtained from the MODerate resolution Imaging Spectroradiometer (MODIS) data.

15 We found that relationships between cloud properties $\left(N, \tau_{\text {cld }}, r_{e}\right)$ and aerosol optical depth are time-dependent (morning versus afternoon). Observed time-dependent changes of cloud properties, associated with aerosol loading, control the variability of surface radiative fluxes. In comparison with pristine clouds, the polluted clouds are more transparent in the afternoon due to smaller cloud fraction, smaller optical depth and larger droplets. As a result, the corresponding correlation between the surface radiative flux and $\tau_{a}$ is positive (warming effect of aerosol). Also we found that relationship between cloud fraction and aerosol optical depth is cloud size dependent. The cloud fraction of large clouds (larger than $1 \mathrm{~km}$ ) is relatively insensitive to the aerosol amount. In contrast, cloud fraction of small clouds (smaller than $1 \mathrm{~km}$ ) is strongly positively correlated with $\tau_{a}$. This suggests that an ensemble of polluted clouds tends to be composed of smaller clouds than a similar one in a pristine environment. One should be aware of these time- and size-dependent features when qualitatively comparing $N-\tau_{a}$ relationships obtained from the satellite observations, surface measurements,

Relationships between aerosol optical depth and cumulus fraction

E. I. Kassianov et al.

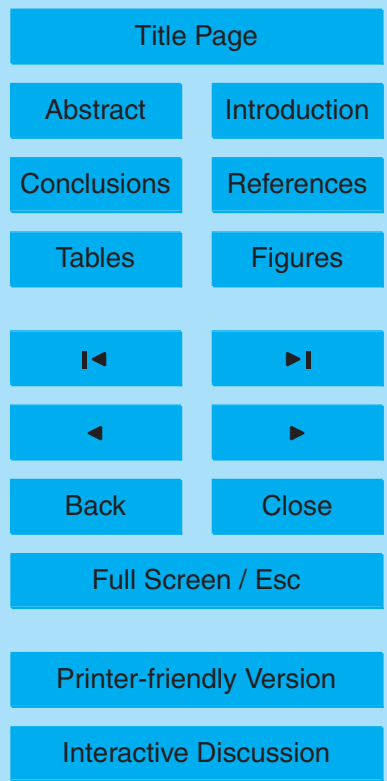

11798 
and model simulations.

\section{Introduction}

The influence that aerosols may have on clouds has been a topic of increasing interest in recent years (e.g., Lohmann and Feichter, 2005 and bibliography therein). Aerosols 5 may have a significant impact on cloud properties by (i) suppressing convection due to reduced surface fluxes (e.g., Feingold et al., 2005; Jiang and Feingold, 2006), (ii) changing optical and microphysical properties of cloud and precipitation (e.g., Twomey, 1977; Albrecht, 1989), and (iii) the altering the stability of the atmosphere due to absorbing sunlight and heating the atmosphere (e.g., Hansen et al., 1997, Johnson et al., 10 2004).

The recent increase of interest in the aerosol-cloud relationship has been fueled largely by satellite observational studies (e.g., Sekiguchi et al., 2003; Koren et al., 2005; Kaufman et al., 2005). Sekiguchi et al. (2003) used two datasets obtained from the National Oceanic and Atmospheric Administration's (NOAA's) Advanced Very High 15 Resolution Radiometer (AVHRR) and Polarization and Directionality of the Earth's Reflectances (POLDER), respectively. They showed that a positive correlation between cloud fraction $N$ of water clouds and aerosol number density concentration exists in most regions of the world (ocean and land) and all seasons. Koren et al. (2005) evaluated the aerosol effect on deep convective and high cloud fields over the North Atlantic Ocean using three months (June-August 2002) of MODerate resolution Imaging Spectroradiometer (MODIS) data. They found a strong correlation between the aerosol optical depth $\tau_{a}$ and cloud properties in three regions with different meteorology and aerosol types. In particular, they demonstrated a consistent and monotonic increase in $N$ with $\tau_{a}$. Similar results were obtained for the shallow clouds over the Atlantic Ocean (Kaufman et al., 2005).

The aerosol-cloud relationship also has been investigated using ground-based observations (e.g., Norris, 2001; Warren et al., 2007; Kaufman and Koren, 2006). A

Relationships between aerosol optical depth and cumulus fraction

E. I. Kassianov et al.

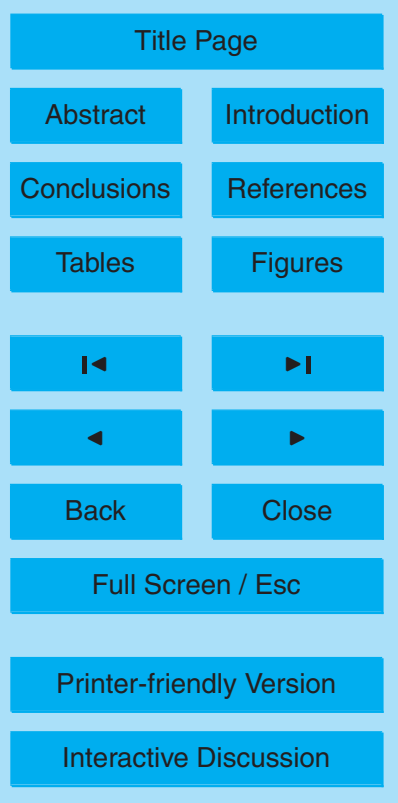

EGU 
recent study conducted by Kaufman and Koren (2006) attempted to quantify the effect of pollution and smoke aerosols on water clouds. Data from Aerosol Robotic Network (AERONET) observations were collected around the globe for each month during a 12-month period and subdivided into continental, coastal/oceanic, and biomass burn5 ing subsets. They found an increase in $N$ with an increase in aerosol loading and an inverse dependence on the aerosol absorption of sunlight. Also, they demonstrated that this relationship is invariant to aerosol type and location. Conversely, multi-year synoptic cloud observations over the Indian Ocean show that low-level cloud cover (dominated by cumulus clouds) increases over time when concentration of absorbing 10 aerosol (soot) presumably has increased greatly (Norris, 2001). Similar synoptic studies have been carried out more recently (Warren et al., 2007) that demonstrated a very weak correlation between cloud amount variability and smoke. This study (Warren et al., 2007) confirmed the previous finding (Norris, 2001). The occurrence of elevated aerosol layers during the surface observations is one possible reason for such a quan15 titative difference (reduction/increase of $N$ versus aerosol absorption) (e.g., Feingold et al., 2005).

Here, we revisit the aerosol-cloud relationship with surface and satellite observations using a new 5-year aerosol and cloud climatology at the Atmospheric Radiation Measurement (ARM) Climate Research Facility (ACRF) Southern Great Plains (SGP) site.

20 As in Kaufman and Koren (2006), we focus on $N$ response to $\tau_{a}$ changes. However, instead of analyzing all types of water clouds, we consider only fair-weather cumulus (FWC) clouds, which are small in the horizontal extend (in comparison with stratocumulus clouds) and are more susceptible to the aerosol effects. In particular, the sensitivity of the aerosol-cloud relationship to cloud size is investigated. In this paper, we use the 25 term cloud size as the cloud chord length (CCL) equivalent. The CCL is defined as the length of the cloud slice that passed directly overhead in wind direction. Also, we use independent measurements of clouds and aerosols to reduce the effects of cloud (aerosol) contamination on the surface-derived $\tau_{a}(N)$. Since the largest increase of $N$ with $\tau_{a}$ reported in the literature is observed when aerosol absorption is weak (Kaufman

\section{Relationships between aerosol optical depth and cumulus fraction}

E. I. Kassianov et al.

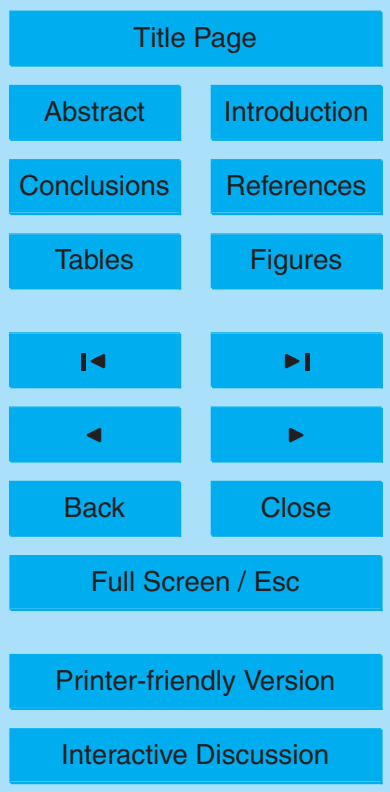

EGU 
and Koren, 2006), we included in our analysis only relatively non-absorbing aerosols. Their average single-scattering albedo $\varpi_{0}$ is about 0.95 and is typical for the ACRF SGP site (e.g., Delene and Ogren, 2002; Andrews et al., 2004). Finally, we considered only cases with well-mixed boundary conditions and without elevated aerosol layers 5 (e.g., from agricultural burning).

The paper is organized as follows. The observations of aerosol, cloud, thermodynamical, and radiative properties at the ACRF SGP site are described in Sect. 2. Section 3 presents case results. Section 4 describes 5 -year statistics related to the $N-\tau_{a}$ relationship and sensitivity of this relationship to the cloud size. A discussion of 10 our results is presented in Sect. 5, and our main findings are summarized in Sect. 6.

\section{Surface and satellite observations}

During spring and summer, the meteorological conditions can be favorable for convection and for development of FWC clouds; therefore, the period of interest is MayAugust. The data cover five summers (2000-2004) at the ACRF SGP Central Facility 15 (Stokes and Schwartz, 1994). Different sensors and instruments located at this Facility have been used to continuously sample the radiation budget components at the Earth's surface, standard meteorological variables and aerosol properties in the site. Below, we outline relevant surface measurements, supplemental satellite observations, and quantities derived from them.

20 Cloud properties were obtained from the ARM Active Remotely Sensed Clouds Locations (ARSCL) value-added product (VAP). The ARSCL VAP includes observations from the 35-GHz cloud radar, micropulse lidar (MPL), and laser ceilometer, and provides the best estimate of cloud boundaries (Clothiaux et al., 2000). The temporal resolution of the ARSCL VAP is $10 \mathrm{~s}$. The selected FWC clouds have cloud-base and cloud-top heights less than $3 \mathrm{~km}$ and $6 \mathrm{~km}$, respectively. Movies from the Total Sky Imager (TSI) were used to evaluate the selection of FWC clouds and to eliminate days with agricultural burning aerosol. This type of aerosol is typically highly absorb-

Relationships between aerosol optical depth and cumulus fraction

E. I. Kassianov et al.

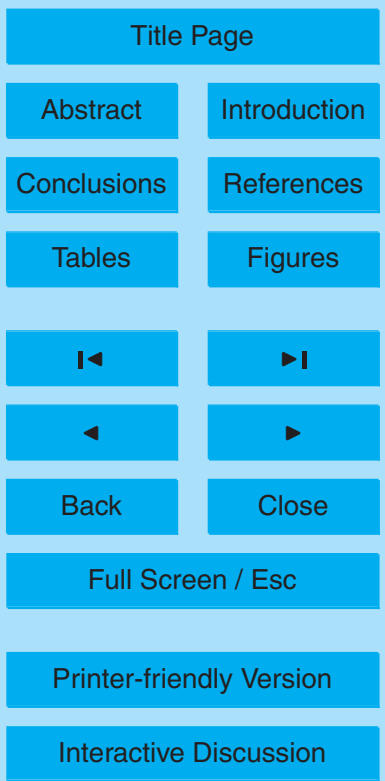


ing (single-scattering albedo $\varpi_{0}$ is relatively small). Note, that $\varpi_{0}$ of biomass burning aerosol is a function of source (e.g., fuel type, combustion regime) and aerosol age (e.g., Ferrare et al., 2006; Mitchell et al., 2006). Such selection of FWC clouds, which combines ARSCL and TSI observations, is laborious; however, it gives a robust multi5 year dataset (Berg and Kassianov, $2007^{1}$ ).

Cloud observations at the ACRF SGP site were accompanied by independent aerosol measurements. In particular, cloud-screened values of aerosol optical depth $\tau_{a}$ were obtained from the Multi-filter Rotating Shadowband Radiometer (MFRSR). The MFRSR provides measurements of the total, direct and diffuse solar irradiances at six 10 wavelengths $(0.415,0.5,0.615,0.673,0.87$, and $0.94 \mu m)$. The sampling interval is $20 \mathrm{~s}$. The direct irradiances are used to derive spectral values of the $\tau_{a}$ (e.g., Harrison and Michalsky, 1994; Alexandrov et al., 2002). A long-term dataset of MFRSR-derived $\tau_{a}$ is available for the SGP site (e.g., Michalsky et al., 2001, Andrews et al., 2004). We apply a cloud-screen algorithm based on an approach suggested by Alexandov et 15 al. (2004) to yield cloud-screened $\tau_{a}$ values obtained for five summers (2000-2004). As a result of cloud screening, $\tau_{a}$ represents column-integrated aerosol optical depth in the clear-sky areas. The $\tau_{a}$ is a function of the aerosol mass loading and of the scattering, and absorption efficiences, which depend on the aerosol size distribution and composition. Below we use the terms aerosol loading, burden, and concentration 20 to describe the $\tau_{a}$ changes. We emphasize that this study uses independent measurements of clouds (ARSCL data) and aerosols (MFRSR data) making it possible to reduce the effects of aerosol contamination on the estimated cloud fraction, and thus on the relationship between $N$ and $\tau_{a}$.

In addition to the MFRSR, we apply observations from the surface Aerosol Observ25 ing System (AOS) (e.g., Sheridan et al., 2001), which includes a nephelometer and a particle soot absorbance photometer to measure scattering and absorption coefficients of dried aerosols, respectively. In particular, we estimate the single-scattering albedo

\footnotetext{
${ }^{1}$ Berg, L. and Kassianov, E.: Temporal variability of fair-weather cloud statistics at the ARCF ASG Site, J. Climate, in review, 2007.
}

\section{Relationships between aerosol optical depth and cumulus fraction}

E. I. Kassianov et al.

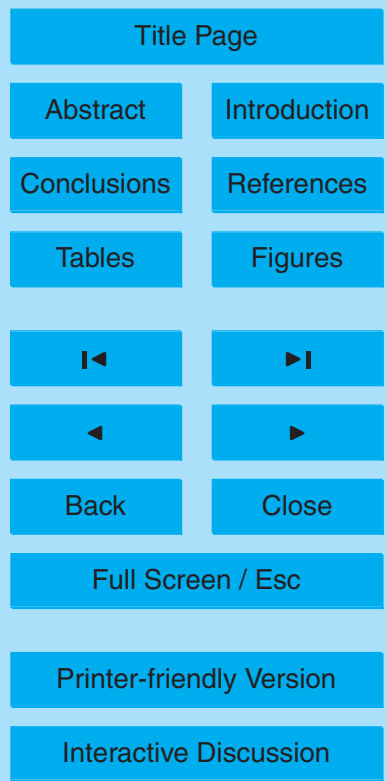


$\varpi_{0}$ from these coefficients. Meteorological variables were measured using a number of different instruments. Multi-year data from the Surface Meteorological Observation System (SMOS) are used to characterize meteorological and thermodynamical parameters, such as air temperature, relative humidity, and wind speed/direction. These 5 parameters, along with profiles of the thermodynamical state and wind speed/direction from a balloon-born sounding system (BBSS), are applied in our analysis as well. Balloons are typically launched four times a day, and the BBSS-derived parameters represent 10-s observations during a free-balloon ascent. Wind speed at cloud base is determined from the $915-\mathrm{MHz}$ wind profiler. The 1-min broadband shortwave (SW) 10 and longwave (LW) radiation are collected from the Sky Radiation (SKYRAD) network (e.g., http://www.arm.gov/instruments/instrument.php?id=skyrad).

Surface-based measurements are supplemented by collocated and coincident satellite observations. The MODerate resolution Imaging Spectroradiometer (MODIS) instrument aboard the Terra and Aqua satellites provides high-resolution measurements of reflectance in 36 spectral bands. The Terra and Aqua satellites view the entire earth's surface every 1 to 2 days and cross the SGP site in opposite directions at about 17:00 UTC and 20:00 UTC, respectively. We apply the 1-km resolution MODIS cloud retrievals (MOD06/MYD06, Collection 5) in two ways to (i) estimate effective radius of droplets $r_{e}$ and cloud optical depth $\tau_{\text {cld }}$ and (ii) ensure that the effect of cirrus contamination on the estimate of FWC properties is not substantial. We use the MODIS-derived $r_{e}$ to evaluate the sensitivity of the $N-\tau_{a}$ and $\tau_{\text {cld }}-\tau_{a}$ relationships to the cloud microphysical changes. The next section illustrates how the integrated dataset of critical variables described here such as clouds, aerosol, meteorology, and thermodynamics obtained from surface and satellite observations can be used to study

\section{Relationships between aerosol optical depth and cumulus fraction}

E. I. Kassianov et al.

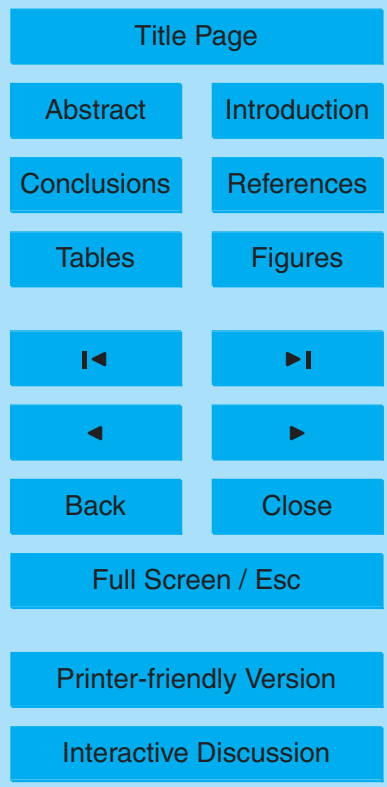




\section{A Representative case study}

The differences in meteorological (e.g., wind speed/direction) and thermodynamical (e.g., relative humidity and temperature profiles) properties could have more impact on the day-to-day cloud properties than differences in aerosol loading (e.g., Jiang et al.,

5 2006; Lohman et al., 2006; Guo et al., 2007). In addition, the vertical distribution of aerosol may affect substantially the cloud fraction (e.g., Feingold et al., 2005). To reduce the influence of the meteorological/thermodynamical properties and the vertical structure of aerosol on the $N$ variability, the following criteria are applied. First, we select days having similar meteorological/thermodynamical conditions. For example, we 10 consider days with similar wind speed/direction and thermodynamical profiles. Second, we exclude cases with elevated aerosol layers. The days of July 5 and July 8, 2002, for example, meet the above criteria while having widely different aerosol burdens.

Figure 1 shows the TSI images for these two days. Visual comparison of these images illustrates how aerosol may obscure clouds and clear sky from a surface observer.

15 For the clean day (5 July), one can readily distinguish clouds against a blue sky (Fig. 1). However, for the polluted day (8 July), we have a "dirty" and blurry image and clouds appear much less distinct (Fig. 1). Since aerosol is mostly non-absorbing $\left(\varpi_{0} \sim 0.95\right)$ for the considered days, the observed obscuring effect is attributed mainly to the large aerosol loading (Fig. 2). In comparison with the clean day, the polluted day is characterized by a large aerosol burden: $\tau_{a} \sim 0.6$ at wavelength $0.5 \mu \mathrm{m}$, which is about twice as large as that for the clean day (Fig. 2). From the MPL images, the selected days have no elevated aerosol layers with most aerosol located below $3 \mathrm{~km}$ within the boundary layer (Fig. 3). In addition, one can see that clean and polluted clouds have similar cloud base heights $(\sim 1.5 \mathrm{~km})$. Such similarity of the cloud base heights can be explained by close agreement between the thermodynamical properties (Fig. 4). Also, the SMOS-derived surface winds have comparable speeds $\left(\sim 4-6 \mathrm{~m} \mathrm{~s}^{-1}\right)$ and similar preferred direction from the southeast for these days (not shown).

To ensure that the effect of cirrus contamination on the estimation of FWC proper-

\section{Relationships between aerosol optical depth and cumulus fraction}

E. I. Kassianov et al.

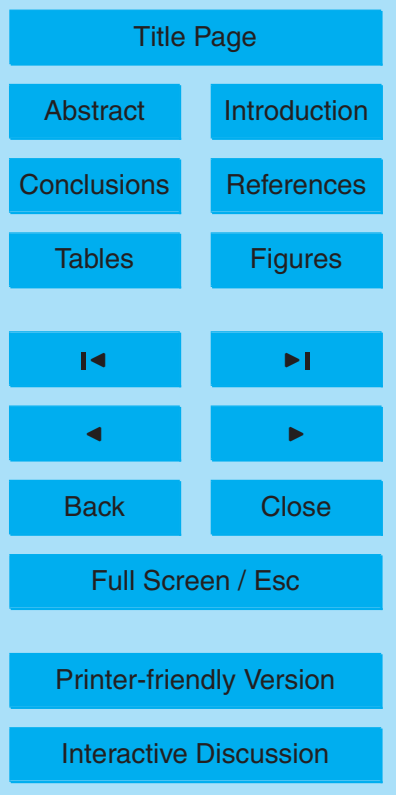


ties is not substantial, we use the MODIS observations. Figure 5 shows images of the MODIS-derived cloud phase. For the clean day ( 5 July), both cirrus and liquid clouds occur (Fig. 5). We estimate the fraction of cirrus clouds as the ratio of the number of pixels with cirrus clouds to the total number of cloud pixels. Cirrus fraction is esti5 mated for different regions surrounding the SGP site. We use labels $A, B$, and $C$ for large, moderate, and small regions, respectively. The fraction of cirrus clouds is about $10 \%$ and almost region-independent. In addition to the cloud phase determination, we use the MODIS observations to examine the effective radius of droplets $r_{e}$. Here $r_{e}$ is defined as the ratio of the third to second moments of the particle size distribu10 tion. Figure 6 illustrates frequency distributions of $r_{e}$ obtained for region A from the MODIS cloud product. Similar results are obtained for other regions (not shown). The frequency distributions of $r_{e}$ are constructed to summarize the frequency with which each $r_{e}$ value occurs in the MODIS images. One can readily see that frequency distributions derived for clean and polluted days are different (Fig. 6a). For large droplets $15\left(r_{e}>10 \mu \mathrm{m}\right)$, some of these differences can be attributed to the cirrus contamination of the MODIS retrievals. However, there is a substantial difference for small droplets $\left(r_{e}<10 \mu \mathrm{m}\right)$ as well (Fig. 6a). From the MODIS data, we can conclude that polluted clouds have smaller droplets. This is consistent with previously reported results, which were obtained from observations (e.g., McFarquhar et al., 2004; Koren et al., 2005) and model simulations (e.g, Xue and Feingold, 2006; Guo et al., 2007). Since liquid water path (LWP) is proportional to the product of $\tau_{\text {cld }}$ and $r_{e}$ (e.g., Stephens, 1994) and polluted clouds are optically thicker (Fig. 6b) and have smaller droplets (Fig. 6a), it appears that the LWP is not sensitive to the aerosol loading for the cases considered here.

25 Let us consider the diurnal evolution of $N$ for clean and polluted clouds (Fig. 7). Here the $N$ represents the hourly averaged $N$ obtained from the ARSCL data. The striking feature is that under polluted conditions, clouds suddenly disappear in the afternoon (after 20:00 UTC). A possible explanation might be that the ARSCL measurements have limitations. For example, the ARSCL instruments have a narrow field-of-view and

Relationships between aerosol optical depth and cumulus fraction

E. I. Kassianov et al.

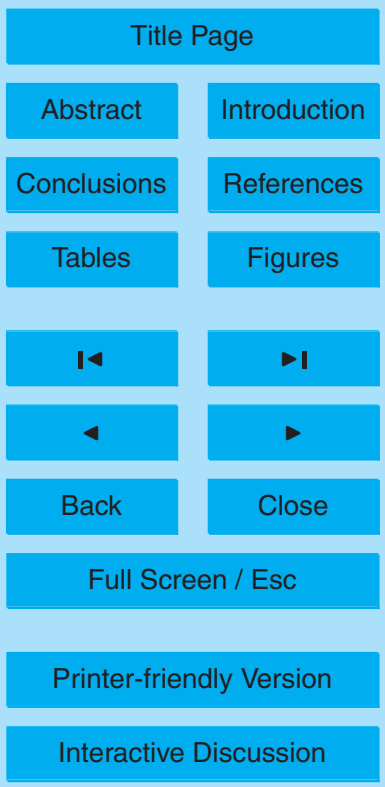


only detect clouds that occur directly above them. As a result, the $N$ obtained from such measurements may not be representative of a larger area surrounding these instruments (e.g., Berg and Stull, 2002; Kassianov et al., 2005a). However, visual inspection of the TSI images confirms that the FWC clouds faded away sharply after 20:00 UTC

5 (not shown). Compared to clean clouds, polluted clouds have much smaller $N$ in the afternoon (after 20:00 UTC) (Fig. 7). Can we observe similar difference between clean and polluted clouds from the long-term observations? The next section addresses this issue.

\section{Climatology}

10 The case study presented in the previous section suggests that clean and polluted clouds may have distinct differences in terms of the diurnal variability of the cloud fraction (Fig. 7). To evaluate the daytime-dependence of this difference, we separate the 5 -year climatology into two large groups based on time of day. These two groups represent data obtained in the morning (before 20:00 UTC) and afternoon (after 20:00 UTC),

15 respectively. For the ARCF site, local time (LT) is related to UTC as LT=UTC-6. The strong diurnal cycle of $N$ associated with thermodynamical state variables and radiative properties has been frequently demonstrated (e.g., Brown et al., 2002). For the given 5-year dataset, the mean $N$ grows in the early part of the day and reaches its maximum ( 35\%) at around 20 UTC and then declines to around 15\% at 24:00 UTC 20 (Berg and Kassianov, 2007 ${ }^{1}$ ). Therefore, the data presented here are separated into two groups, before and after 20:00 UTC. Such separation (i) relates to the time when the maximum mean value of $N$ was observed (Berg and Kassianov, 2007 ${ }^{1}$ ) and (ii) represents the evolution of the FWC clouds from their initial growth (morning) to their final dissipation (afternoon).

25 To study the relationship between $N$ and $\tau_{a}$, we perform the following three-step data processing procedure (analogous to Sekiguchi et al., 2003). First, we sort the hourly averaged $N$ values into seven bins of $\tau_{a}($ at $0.5 \mu \mathrm{m}$ ) with the same increment of 0.1 .

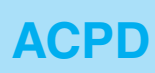

7, 11797-11837, 2007

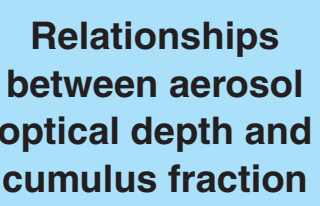

E. I. Kassianov et al.

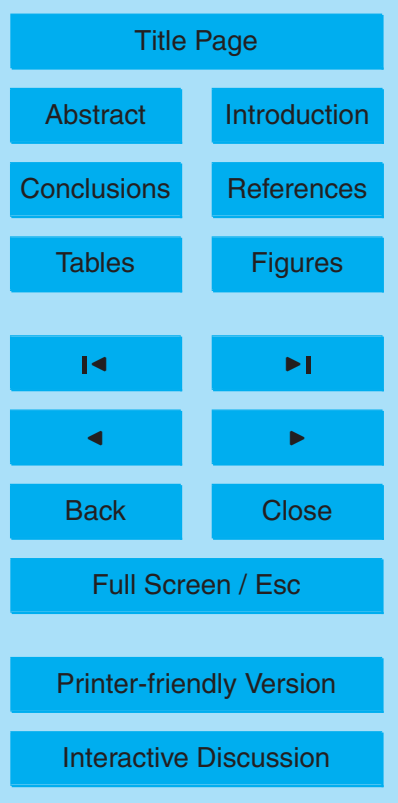

EGU 
Second, we calculate the mean value of $N$ for each bin. Finally, these mean bin values are used to produce scatterplots of $N$ as function of $\tau_{a}$. Since the frequency distribution of $\tau_{a}$ is not uniform (Fig. 8), the number of sorted $N$ values is bin-dependent. In other words, some bins have fewer $N$ values. For example, the first and last bins compared 5 to others have relatively small number $(\sim 10)$ of $N$ values (Fig. 8). As a result, the corresponding mean bin values of $N$ are less statistically robust toward both ends of the range of aerosol optical depth.

We assume that an association between $N$ and $\tau_{a}$ can be described by a linear regression. Figure 9 illustrates that $N$ is correlated with $\tau_{a}$ in the afternoon and the 10 absolute value of the correlation coefficient is relatively high $|r| \sim 0.83$ (Table 1a). We determine the significance of the observed correlation coefficient $r$ from the $t$-statistics. In particular, we use $p$ value for the $t$-test of the correlation coefficient equals to 0 , where small $p$ value indicates that the correlation between $N$ and $\tau_{a}$ is significantly different from 0 . For a given correlation coefficient $(|r| \sim 0.83)$, the attained significance 15 level is small $p \sim 0.04$. This means that the regression model ( $N$ versus $\tau_{a}$ ) is usable. Also, Fig. 9 shows that $N$ decreases with an increase of $\tau_{a}$ in the afternoon. This is consistent with the case study results in Sect. 3 . The slope of the regression line is about -0.13 (Table 1a) and is significantly different than 0 . Note, that the slope can be interpreted as the sensitivity of association. The sensitivity also can be expressed in terms of "absolute percent" (Warren et al., 2007) or changes of $N$ in units of percentage points. We will use the "absolute percent" term in our paper. For example, $N$ decreases from 0.31 to 0.24 in the afternoon, and thus, the change in $N$ is $7 \%$.

Figure 9 illustrates the strong negative correlation between $N$ and $\tau_{a}$ in the afternoon. The opposite is true in the morning (Fig. 9) when a relatively weak positive correlation $(r \sim 0.41)$ is observed. The corresponding $p$ value is relatively large $(p \sim 0.36$ in Table 1a) and indicates that the strength of the correlation between $N$ and $\tau_{a}$ in the morning is weak. Let us demonstrate that the observed positive correlation in the morning is spurious. In addition to the original regressions (Fig. 9), we constructed two alternatives by only using six points. The first point, which corresponds to the

\section{Relationships between aerosol optical depth and cumulus fraction}

E. I. Kassianov et al.

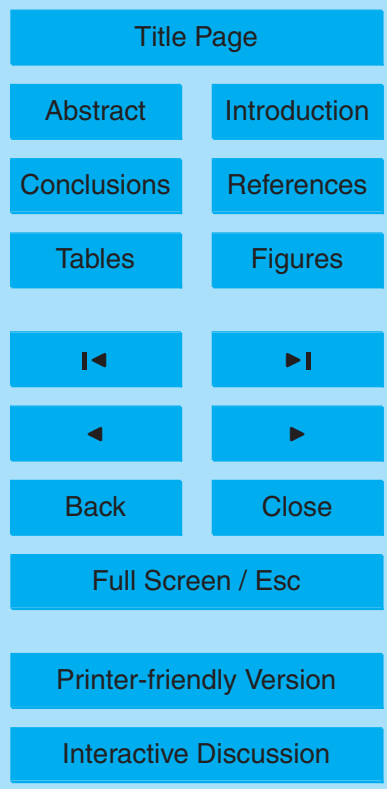


first bin $\left(\tau_{a}<0.1\right)$, is excluded from consideration. As a result, the original (based on seven points) and additional (based on six points) regressions are different in terms of sign and magnitude (Tables 1a, b). However, the corresponding parameters of the afternoon regression are not sensitive to the number of points (seven versus six) (Ta5 bles $1 \mathrm{a}, \mathrm{b})$. The obtained results suggest that thermodynamical and dynamical effects primarily control the FWC development in the morning (early phase), while the role of aerosols on the FWC evolution increases in the afternoon (later phase).

So far, we considered the total $N$, which combines contributions from both small and large clouds. How sensitive is the relationship between $N$ and $\tau_{a}$ to the horizontal cloud 10 size? To estimate this sensitivity, we separate the 5-year data into two additional groups based on the mean horizontal cloud size. For the 5-year dataset, the mean horizontal cloud size is about $1 \mathrm{~km}$ (Berg and Kassianov, 2007 ${ }^{1}$ ). Data from ARSCL and the 915$\mathrm{MHz}$ radar wind profiler were combined to yield the cloud chord length (CCL) (Berg and Kassianov, $2007^{1}$ ). Since the temporal resolution of the ARSCL VAP is $10 \mathrm{~s}$ and 15 the nominal error of the wind speed measured with the wind profiler is $\pm 1 \mathrm{~ms}^{-1}$, the corresponding spatial resolution of CCL $\left(I_{\mathrm{min}}\right)$ is $0.1 \mathrm{~km}$. The largest value of $\mathrm{CCL}$ $\left(I_{\max }\right)$ in our analysis is set as $6 \mathrm{~km}$. A number of different factors can contribute to large values of CCLs. For example, the distance between individual clouds and their parts/fragments can be similar to or less than $I_{\min }$, and some clouds can be tilted and 20 hence overlap for a nadir looking surface instrument. Similar to Rodts et al. (2003), the cloud fraction $N$ has been defined in terms of the $N$ density $\left(\alpha_{f}\right)$ as

$N=\int_{I_{\min }}^{I_{\max }} \alpha_{f}(/) d l$

$\alpha_{f}(I)=\frac{1}{L} n(/) \times /$,

where $n$ is the number of clouds with a given CCL, / is the CCL, and $L$ is the total length

of interest. We have demonstrated (Berg and Kassianov, $2007^{1}$ ) that such spatial cloud 11808

Relationships between aerosol optical depth and cumulus fraction

E. I. Kassianov et al.

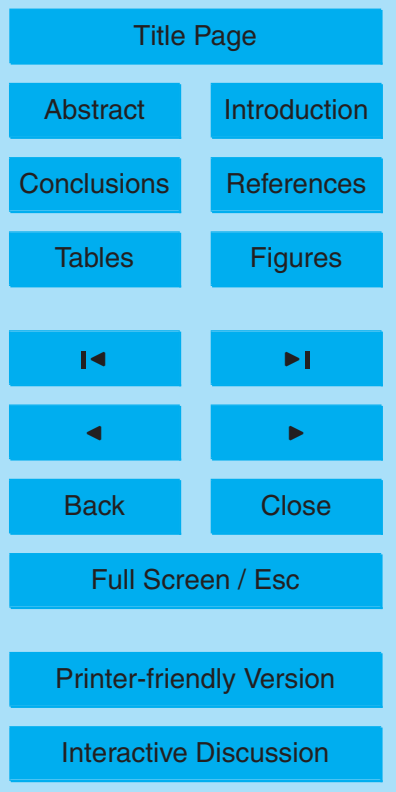

EGU 
fraction $N$ is in good agreement with conventional temporal cloud fraction, which is defined as the fraction of time that a cloud is overhead (e.g., Dong et al., 2006).

For small clouds $(\mathrm{CCL}<1 \mathrm{~km})$, a positive trend is observed: the cloud fraction $N$ increases from 0.15 to 0.22 ( $7 \%$ change) with increasing aerosol optical depth (Fig. 10).

5 The linear regression model does appear to be a reasonable description of the observed relationship between $N$ and $\tau_{a}$ (Fig. 10). In particular, the corresponding correlation coefficient is $r \sim 0.67$ and attained significance level is $p \sim 0.10$ (Table 1a). The parameters of the considered linear regression depend on the number of points used to compute it, but the sign of the trend is unchanged (Tables 1a, b). In contrast, the 10 cloud fraction of large clouds shows poor correlation with $\tau_{a}$ (Fig. 10): the slope is negative and near zero (Table 1a). The negative trend becomes more pronounced if observations with small $\tau_{a}$ (less than 0.1 ) are not considered (Tables 1a, b). These results (Fig. 10) suggest that, under polluted conditions, the relative contribution of small clouds to the total $N$ increases. It should be mentioned that these two groups are 15 not independent. For example, a large cloud can be divided into smaller pieces (fragments) during its evolution. In our analysis, these pieces of a former large cloud are considered as small clouds. The inverse process may also occur when small clouds merge into a larger one.

Since the contribution of the small clouds, which have a cloud size smaller than $1 \mathrm{~km}$, 20 to the total cloud fraction of FWC clouds is substantial (Berg and Kassianov, 2007 ${ }^{1}$ ), it is difficult to infer distinct cloud-size compositions of clean and polluted clouds from the available 1-km resolution MODIS data. We will discuss this and other issues associated with the unique properties of the FWC clouds and the operational satellite retrievals in the next section.

\section{Discussion}

Our results (previous sections) provide observational support that aerosols may influence the formation and evolution of low-level clouds. However, these results reveal

\section{Relationships between aerosol optical depth and cumulus fraction}

E. I. Kassianov et al.

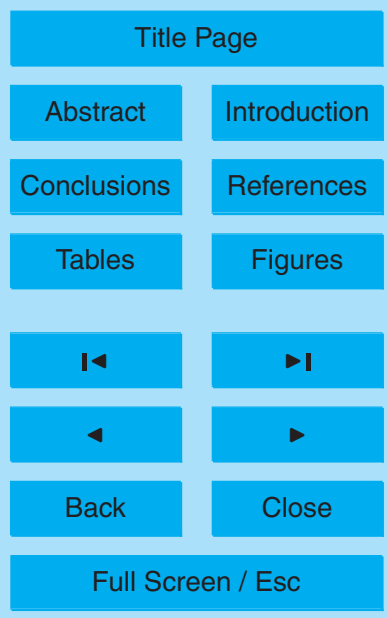

Printer-friendly Version

Interactive Discussion 
little about the mechanisms associated with the aerosol effects that are responsible for the changes of $N$. Recent large-eddy simulation (LES) studies suggested some of these mechanisms by examining the response of warm continental cumulus clouds to aerosol loading (e.g., Xue and Feingold, 2006; Jiang and Feingold, 2006). For 5 example, Jiang and Feingold (2006) showed that aerosol radiative effects can significantly modify atmospheric heating profiles, reduce surface radiative fluxes, and thus decrease convection and the cloud fraction. It has also been found that $N$ is sensitive to microphysical-dynamical feedback (Xue and Feingold, 2006). In particular, dropsize-dependent evaporation rates may be responsible for changes in cloud size and 10 cloud fraction (Xue and Feingold, 2006). In Sects. 5.1 and 5.2, we consider both the observed radiative and microphysical effects associated with aerosol loading.

\subsection{Aerosol radiative effects}

As the aerosol loading increases, the aerosol blocks the surface from the incoming solar radiation. As a result, both the surface heating and the upward convection decrease 15 (Jiang and Feingold, 2006). On the other hand, less intensive convection reduces $N$, leads to less cloud shading of the ground from the sun, and thus, increases the surface insolation/heating and the upward convection. Here the surface insolation is defined as the amount of sunlight reaching the surface. Therefore, $\tau_{a}$ increasing and $N$ decreasing can produce opposite changes in the surface insolation and the subsequent 20 convection.

Aerosol and clouds affect both SW and LW fluxes, making it difficult to predict different and possibly compensating changes in the surface energy balance. To estimate the sensitivity of the net $S W, L W$, and total $(S W+L W)$ fluxes at the surface, we separate the 5 -year data into two groups. The net flux is defined as the difference between incoming 25 and outgoing radiative fluxes. Similar to the previous analysis of $N$ (Sect. 4), these two groups are selected based on the time of day (morning and afternoon). As expected, the net SW flux contributes most of the total flux (Table 2). In the morning, the SW and the LW fluxes have opposite trends, and thus, due to these partly compensating

Relationships between aerosol optical depth and cumulus fraction

E. I. Kassianov et al.

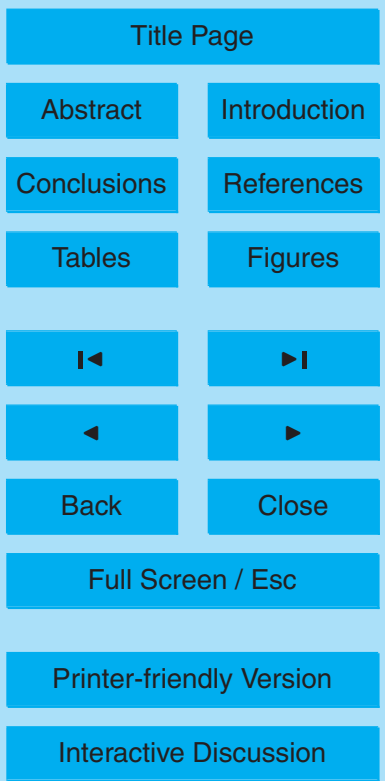


changes the relationship between the total flux and $\tau_{a}$ is weak (Table 2). It is interesting that a similar weak relationship is observed between $N$ and $\tau_{a}$ in the morning (Fig. 9, Table 1a). In the afternoon, both the SW and the LW fluxes have positive trends. Such synchronized changes in the SW and LW fluxes lead to the positive and strong 5 correlation between the total flux and $\tau_{a}$ observed in the afternoon (Table 2). The corresponding correlation coefficient $(r \sim 0.79)$ is similar to that $(|r| \sim 0.83)$ obtained for the cloud fraction (Table 1a). Contrary to the model results, which demonstrated the reduction of both the cloud fraction and the total flux with aerosol loading (Jiang and Feingold, 2006), the observed changes of the total flux and $N$ have opposite signs in 10 the afternoon (Table 1a, Table 2).

Aerosols can affect the surface radiation fluxes in several different ways. Let us illustrate the aerosol radiative effect by using the incoming SW flux as an example. The LW and the total fluxes can be described similarly. We start with the plane-parallel approximation and then consider a three-dimensional (3-D) case. In the context of the 15 plane-parallel approximation, the incoming SW flux $F_{p p}$ can be written as

$$
F_{p p}=(1-N) F_{\text {clear }}+N F_{\text {cld }}
$$

where $F_{\text {clear }}$ and $F_{\text {cld }}$ are the downward SW fluxes obtained under clear-sky and cloudy (completely overcast) conditions, respectively.

From Eq. (3), we can estimate the sensitivity of the SW flux to $\tau_{a}$ variations as

$$
20 \frac{\partial F_{p p}}{\partial \tau_{a}}=(1-N) \frac{\partial F_{\text {clear }}}{\partial \tau_{a}}+\frac{\partial N}{\partial \tau_{a}}\left(F_{\text {cld }}-F_{\text {clear }}\right)+N \frac{\partial F_{\text {cld }}}{\partial \tau_{a}}
$$

Three terms in Eq. (4a) determine the magnitude and sign of this sensitivity. Since $F_{\text {clear }}$ decreases with an increase of $\tau_{a}$, the first term is always negative. The sign of the second term is defined completely by the partial derivative of $N$ with respect to $\tau_{a}$ as $F_{\text {cld }}-F_{\text {clear }}<0$. In other words, if $N$ decreases with $\tau_{a}$, the second term is 25 positive and vice versa. The third term is a function of the cloud optical properties and their sensitivity to $\tau_{a}$ variations. Typically, the cloud optical depth $\tau_{\text {cld }}$ increases

\section{Relationships between aerosol optical depth and cumulus fraction}

E. I. Kassianov et al.

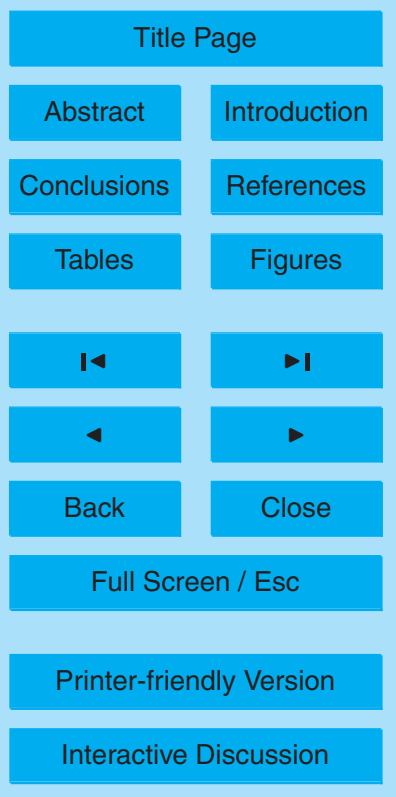

EGU 
with an increase of $\tau_{a}$ (e.g., McFarquhar et al., 2004); the opposite is true for the effective radius of cloud droplets $r_{e}$ (e.g., Lohmann and Feichter, 2005), and thus for the asymmetry parameter $g_{\text {cld }}$. These two factors (increase of $\tau_{\text {cld }}$ and decrease of $g_{\text {cld }}$ ) make the clouds more reflective (or less transparent) and thus lead to the reduction 5 of $F_{\text {cld }}$. Therefore, the sign of the third term tends to be negative. We will discuss the relationship between the MODIS-derived cloud parameters $\left(\tau_{\text {cld }}\right.$ and $\left.r_{e}\right)$ and $\tau_{a}$ in Sect. 5.2 and show that the third term appears to be positive for the FWC clouds .

In a similar manner, the sensitivity of the three-dimensional (3-D) SW flux $F_{3 D}$ to $\tau_{a}$ changes can be estimated as

${ }_{10} \frac{\partial F_{3 \mathrm{D}}}{\partial \tau_{a}}=\frac{\partial F_{1}}{\partial \tau_{a}}+\frac{\partial F_{2}}{\partial \tau_{a}}+\frac{\partial F_{3}}{\partial \tau_{a}}$

where the first, second, and third terms represent partial changes of $F_{3 D}$ due to changes in the aerosol optical characteristics, the cloud macrophysics (e.g., $N, \mathrm{CCL}$ ), and the cloud optical (e.g., $\left.\tau_{\text {cld }}\right)$ properties, respectively. Thus, differences between models and observations (e.g., positive versus negative trend of the total flux) can be explained partially by quantitative and qualitative differences in these terms.

The modeled (Jiang and Feingold, 2006) and observed (Table 1) trends of $N$ are similar in terms of sign (negative). In contrast, the corresponding trends of the net surface fluxes obtained from model simulations and observations have slopes with opposite signs. Thus, our findings suggest that the reduction of the surface flux resulting 20 from an increase of $\tau_{a}$ is not the single nor most important factor for controlling the $N$, as originally suggested (Jiang and Feingold, 2006). The modifications in the atmospheric heating profiles associated with the aerosol absorption may be a reason for the qualitative differences between results obtained from model simulations (Jiang and Feingold, 2006) and observations. Recall, the integrated observational dataset repre25 sents mostly non-absorbing conditions $\left(\varpi_{0} \sim 0.95\right)$, while the model simulations (Jiang and Feingold, 2006) have been performed for absorbing aerosol $\left(\varpi_{0} \sim 0.9\right)$, which can be associated with biomass burning smoke. The corresponding SW radiative heating

\section{Relationships between aerosol optical depth and cumulus fraction}

E. I. Kassianov et al.

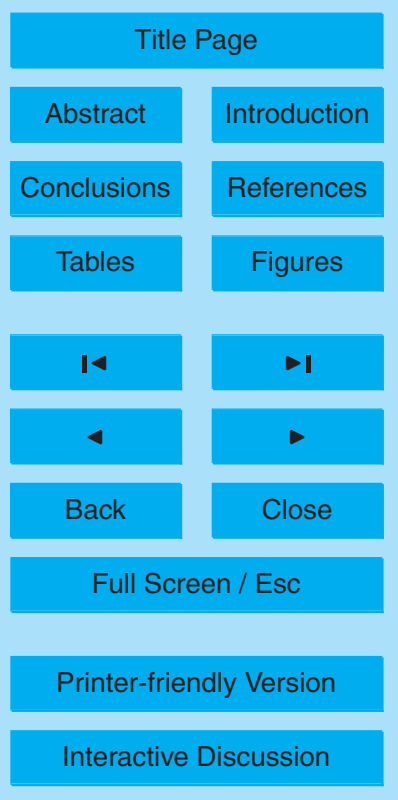

EGU 
rates of the atmosphere may be as much as $6 \mathrm{~K}_{\text {day }}{ }^{-1}$ for this type of aerosol (Jiang and Feingold, 2006).

\subsection{Aerosol microphysical effects}

The importance of aerosols for altering the cloud microphysical properties is well illus5 trated (e.g., Xue and Feingold, 2006; Fan et al., 2007, and bibliography therein). In turn, the microphysical changes of cumulus clouds can substantially modify their amount and optical depth (Lohmann and Feichter, 2005). One reason for this modification has been suggested by Xue and Feingold (2006). An increase in aerosol concentration results in a decrease of cloud droplet size. Therefore, the polluted clouds in compar10 ison with clean clouds have smaller droplets. They found that the smaller droplets of polluted clouds evaporate more readily and cause a more intensive $N$ reduction under the polluted environment. In other words, the droplet size response to aerosol and the drop-size-dependent evaporation rates may be responsible for distinctions between pristine and polluted cloud properties.

15 To estimate the sensitivity of the cloud droplets to the aerosol burdens, we perform an analysis of available satellite data. In particular, we apply two MODIS datasets of cloud properties obtained from the Terra and Aqua observations. From these two datasets, we select cases that meet the following criteria. First, the satellite and surface observations must have occurred on the same days. Second, during the satellite observations there is a well-defined single layer of FWC clouds over both the SGP site and surrounding regions. Again, we consider three different regions centered at the SGP site (Fig. 5). Similar to the case study (described in Sect. 3), we estimate the fraction of cirrus clouds for each region. If, for a given day, this fraction in a region exceeds $10 \%$, we assume that cirrus contamination is high and discard all cloud properties obtained for this day. The selected cloud properties are separated into two bins. The first bin $\left(\tau_{a}<0.2\right)$ and the second bin $\left(\tau_{a}>0.2\right)$ represent clean and polluted conditions, respectively.

Relationships between aerosol optical depth and cumulus fraction

E. I. Kassianov et al.

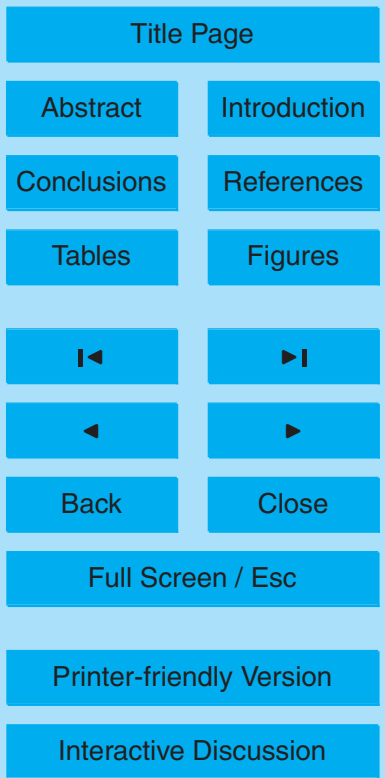


Figure 11a shows the Terra-derived values of $r_{e}$ for three different regions. Each region has a decrease in $r_{e}$ with an increase in aerosol loading and the rate of this decrease (negative trend) is region-dependent (Fig. 11a). The observed negative trend is consistent with the case study results (Fig. 6) and numerous previous stud5 ies. The latter have considered mainly stratus and stratocumulus clouds and provided ample evidences of the droplet size reduction by aerosol (e.g., Lohmann and Feichter, 2005). Such a reduction was originally proposed by Twomey (1977), well-known as the Twomey effect. Contrary to the stratus/stratocumulus related studies, we observe an increase in $r_{e}$ with the aerosol loading for each region using the Aqua observations 10 (Fig. 11b). Note that the Terra and Aqua observations are performed in the morning (17:30 UTC) and in the afternoon (20:00 UTC), respectively. Therefore, we can speculate that for the FWC clouds, the $r_{e}-\tau_{a}$ relationship is time-dependent and may be either negative (morning) or positive (afternoon). In other words, the Twomey effect is apparent only during the development of the FWC clouds and the initial stage of their 15 evolution. Different processes are responsible for the droplet size growth/reduction (e.g., Xu et al., 2005). It seems reasonable from our results that for the FWC clouds the magnitude of these processes and its sensitivity to aerosol amount depend on the time of day.

If the model-suggested direction of causality is from smaller droplets and more inten20 sive evaporation to the more substantial $N$ reduction (Xue and Feingold, 2006), then the $r_{e}-\tau_{a}$ and the $N-\tau_{a}$ relationships should have the same negative trends. However, the observed $r_{e}-\tau_{a}$ and $N-\tau_{a}$ relationships have opposite trends in the afternoon: negative for the $N-\tau_{a}$ (Fig. 9) and positive for the $r_{e}-\tau_{a}$ (Fig. 11). In other words, compared to pristine clouds the polluted ones have larger droplets and smaller horizontal sizes.

25 Therefore, the observations do not support the model-suggested direction of causality associated with smaller droplets of polluted clouds and the drop-size-dependent evaporation rates. On the other hand, the contribution of small clouds increases with the aerosol loading (Fig. 10), as the model predicts (Xue and Feingold, 2006). The observed increase of the small clouds is probably due to a combined effect of (i) en-

\section{Relationships between aerosol optical depth and cumulus fraction}

E. I. Kassianov et al.

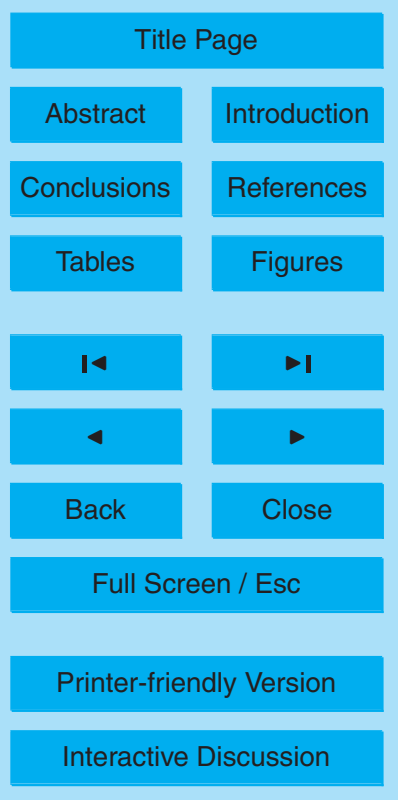


trainment rates, which are inversely proportional to the cloud size (e.g., McCarthy, 1974); (ii) the vertical profiles of heating/cooling and drying/moistening, which are very different for small and large clouds (e.g., Zhao and Austin, 2005); and (iii) the sizedependent dynamical properties of cumulus clouds (e.g., Rodts et al., 2005). As result

5 of the combined effect, the large clouds may last longer than small clouds: the lifetime for simulated small and large clouds is about $18 \mathrm{~min}$ and $25 \mathrm{~min}$, respectively (Zhao and Austin, 2005).

Contrary to the effective radius of cloud droplets $r_{e}$ (Fig. 11), the cloud optical depth $\tau_{\text {cld }}$ is more sensitive to the region selection (Fig. 12). For example, the Terra-derived $10 \tau_{\text {cld }}$ obtained for the region $C$ is nearly twice as small as that for the region A (Fig. 12a). Since $\tau_{\text {cld }} \sim L W P / r_{e}$, such stronger sensitivity is primarily attributed to region-related variations of the LWP. The latter can compensate $r_{e}$ changes associated with the aerosol loading, and as a result, can produce weak dependence between $\tau_{\text {cld }}$ and $\tau_{a}$. In other words, the LWP decrease (increase) may offset the $r_{e}$ reduction (growth). 15 This is illustrated in the Terra-derived cloud product for regions $A$ and $B$. Although the effective radius $r_{e}$ decreases with aerosol (Fig. 11a), the cloud optical depth $\tau_{\text {cld }}$ appear to be independent of $\tau_{a}$ (Fig. 12a). On the other hand, the effective radius $r_{e}$ (Fig. 11b) and cloud optical depth $\tau_{\text {cld }}$ (Fig. 12b) exhibit opposite behavior with $\tau_{a}$ for all regions in the afternoon. This is likely due to the LWP contribution to $\tau_{\text {cld }}$, which appears fairly insensitive to the region selection in the afternoon.

The observed time-dependent $N-\tau_{a}, r_{e}-\tau_{a}$, and $\tau_{\text {cld }}-\tau_{a}$ relationships are mainly responsible for the observed SW flux changes with aerosol (Table 2). For example, in the afternoon the polluted clouds have a smaller cloud fraction $N$ (Fig. 9), larger droplets (Fig. 11) (or larger $g_{\text {cld }}$ ), and smaller optical depth $\tau_{\text {cld }}$ (Fig. 12). The corresponding observed increase of the SW flux (Table 2) can be explained as follows. The smaller cloud amount reduces the cloud shading of the ground from the sun, and thus leads to more intensive surface insolation. In turn, the $\tau_{\text {cld }}$ reduction and $g_{\text {cld }}$ increase make the clouds more transparent and enhance the surface insolation (warming effect) even further. Contrary to the well-known cooling aerosol effect during clear-sky conditions

\section{Relationships between aerosol optical depth and cumulus fraction}

E. I. Kassianov et al.

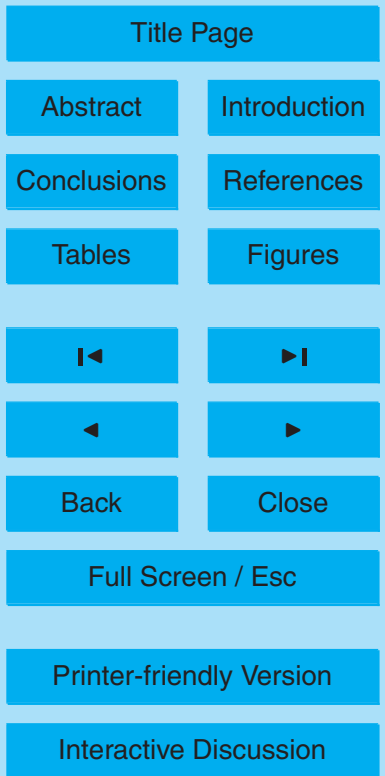


(e.g., Yu et al., 2002), the warming effect of non-absorbing aerosols may be observed in a party cloudy atmosphere. It should be mentioned that the cloud shading effect is a function of the solar zenith angle (SZA), $N$, and cloud aspect ratio (thickness to horizontal size). At constant $N$ and cloud aspect ratio, importance of the cloud shading 5 increases with SZA (the sun gets lower) (e.g., Kassianov et al., 2005b).

Satellite remote sensing of cumulus clouds is inherently difficult as a result of their (i) low amount of liquid water (LWP, $\leq 100 \mathrm{~g} \mathrm{~m}^{-2}$ ), (ii) small sizes ( $\leq 1 \mathrm{~km}$ ), and (iii) complex 3-D geometry. Since the radiative properties of clouds with low LWP are very sensitive to the LWP changes and this sensitivity is a function of $r_{e}$, the retrieval of $\tau$ and $r_{e}$ 10 for such optically thin clouds presents a challenge even for completely overcast cases with relatively weak horizontal variability (Turner et al., 2007). Moreover, the sizes of many cumulus clouds are smaller or comparable to the 1-km resolution of the typical MODIS cloud product. As a result, some pixels from a satellite image are only partially cloud covered and biases in the operational MODIS retrievals, which are based on an assumption that $1-\mathrm{km}$ pixels are completely overcast, may be large. Finally, the strong 3-D radiative effects, associated with the complex geometry of cumulus clouds, complicate their remote sensing matters still further (e.g., Vant-Hull et al., 2007). Therefore, the uncertainties for cumulus retrievals are substantially larger than those for stratus or stratocumulus clouds (e.g., Kato et al., 2006). However, uncertainties for the areaaveraged data considered here are much smaller than uncertainties obtained for each pixel. Moreover, since the FWC clouds are observed by the same MODIS instrument launched on the Terra and Aqua platforms, the biases of the Terra and Aqua observations are expected to be consistent. Therefore, the possible systematic biases of the cumulus retrievals will have no impact on observed trends.

\section{Summary}

The relationship between cloud fraction $N$ of the fair-weather cumulus (FWC) clouds and aerosol optical depth $\tau_{a}$ is assessed using 5-year surface and Terra/Aqua satel-

Relationships between aerosol optical depth and cumulus fraction

E. I. Kassianov et al.

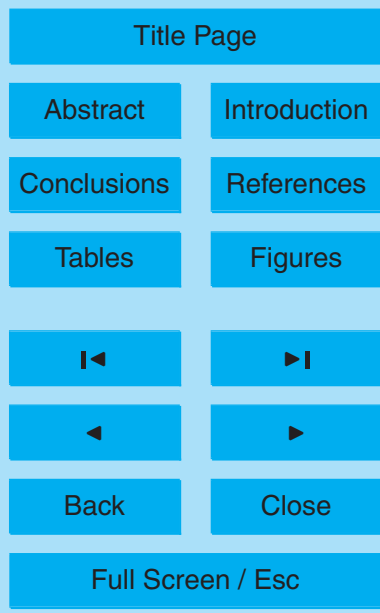

Printer-friendly Version

Interactive Discussion 
lite observations at the Atmospheric Radiation Measurement (ARM) Climate Research Facility (ACRF) Southern Great Plains (SGP) site. To reduce possible contamination of the aerosols on the estimation of $N$ (and vice versa), we use independent datasets of $\tau_{a}$ and $N$ obtained from the Multi-filter Rotating Shadowband Radiometer (MFRSR) 5 measurements and from the ARM Active Remotely Sensed Clouds Locations (ARSCL) value-added product, respectively. Optical depth of the FWC clouds $\tau_{\text {cld }}$ and effective radius of cloud droplets $r_{e}$ are obtained form the MODerate resolution Imaging Spectroradiometer (MODIS) data. The main results are as follows:

1. Both the cloud fraction $N$ and cloud optical depth $\tau_{\text {cld }}$ exhibit a weak positive correlation with aerosol optical depth $\tau_{a}$ in the morning, while this correlation becomes significantly negative in the afternoon. It appears that the role of aerosol in the evolution of the FWC clouds increases as they mature.

2. The effective radius of cloud droplets $r_{e}$ is negatively correlated with $\tau_{a}$ in the morning, while the opposite is true in the afternoon. This suggests that for the FWC clouds the magnitude of droplet size growth/reduction processes and its sensitivity to aerosol amount depend on the time of a day.

3. Time-dependent changes of cloud properties, associated with aerosol loading, control the day-to-day variability of surface radiative fluxes. For example, in comparison with pristine clouds, the polluted clouds are more transparent in the afternoon due to smaller cloud fraction, smaller optical depth, and larger droplets. As a result, the corresponding correlation between the surface radiative flux and $\tau_{a}$ is positive (warming effect of aerosol).

4. Cloud fraction of large clouds (larger than $1 \mathrm{~km}$ ) is relatively insensitive to the aerosol amount. In contrast, the cloud fraction of small clouds (smaller than $1 \mathrm{~km}$ ) is strongly positively correlated with $\tau_{a}$. This suggests that an ensemble of polluted clouds has an increased number of smaller clouds than a similar ensemble in a pristine environment. The observed positive trend supports the model predictions (e.g., Xue and Feingold, 2006).

\section{Relationships between aerosol optical depth and cumulus fraction}

E. I. Kassianov et al.

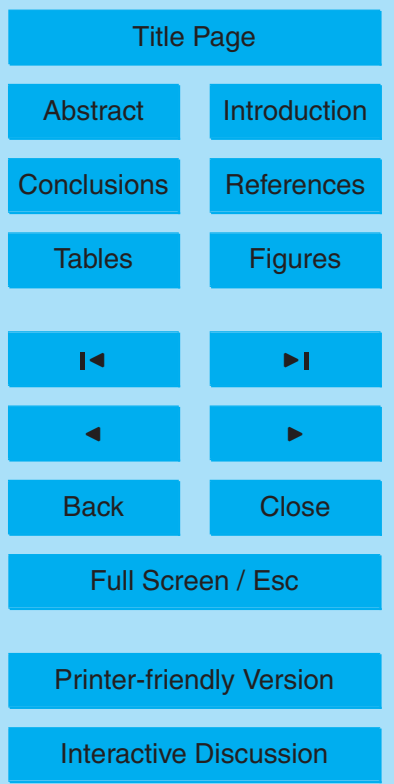


5. The overall picture that emerges is that the $N-\tau_{a}$ relationship depends on both the time of day and the cloud size. One should be aware of these remarkable features when qualitatively comparing $N-\tau_{a}$ relationships obtained from surface measurements, satellite observations, and model simulations. For example, the diurnal time-dependence of the $N-\tau_{a}$ relationship may lie hidden in the dailyaveraged statistics. The same is true for the cloud-size-averaged statistics, which combine the effect of small and large clouds.

6. The integrated dataset of aerosol, cloud, radiative, thermodynamical, and meteorological properties obtained from the surface and satellite observations at the ACRF SGP site presented here provides a new observational constraint, which can be used to ascertain performance and predictions of model simulations. Current and future parameterizations of the FWC clouds should reproduce the observed trends.

We stress that these conclusions are obtained for the nonprecipitating FWC clouds and 15 the mostly non-absorbing aerosols that occur at the ACRF SGP site. Since the SGPobtained statistics appear to be fairly typical of the mid-latitude regions, we expect that the above conclusions may be valid for a range of continental FWC clouds and aerosols.

An area worthy of further research is to extend analysis of the cloud-aerosol relationship by using additional observations/datasets available at the ACRF SGP site. In particular, the Raman lidar $(R L)$ measures the vertical profiles of water-vapor mixing ratio and several aerosol-related quantities (e.g., Ferrare et al., 2006), while the Atmospheric Emitted Radiance Interferometer (AERI) can provide cloud optical depth and effective radius of droplets with high temporal resolution (e.g., Turner, 2005). We plan to use both the RL and AERI observations to better characterize aerosol, cloud and thermodynamical properties, and thus, better understand the aerosol-cloud-radiation interaction.

Acknowledgements. This work was supported by the Office of Biological and Environmental 11818

Relationships between aerosol optical depth and cumulus fraction

E. I. Kassianov et al.

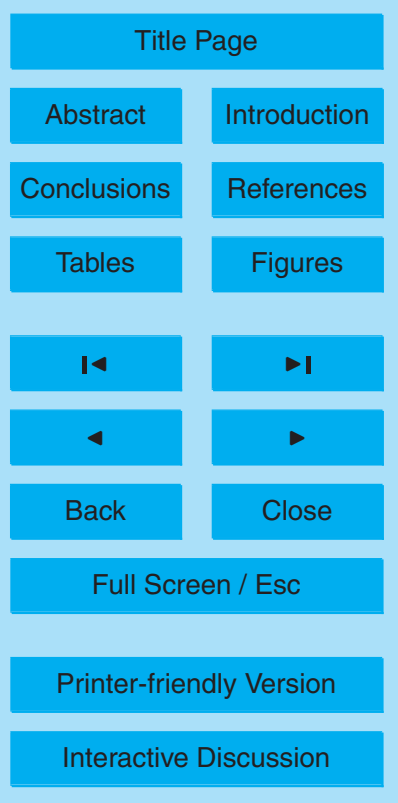

EGU 
Research of the U.S. Department of Energy as part of the Atmospheric Radiation Measurement (ARM) Program. We thank M. Ovtchinnikov and D. Turner for providing useful discussions and valuable suggestions.

\section{References}

5 Albrecht, B. A.: Aerosol, cloud microphysics and fractional cloudiness, Science, 245, 12271230, 1989.

Alexandrov, M. D., Lacis, A. A., Carlson, B. E., and Cairns, B.: Remote sensing of atmospheric aerosols and trace gases by means of multifilter rotating shadowband radiometer. Part I: Retrieval algorithm, J. Atmos. Sci., 59, 524-543, 2002.

Alexandrov, M., Marshak, A., Cairns, B., Lacis, A., and Carlson, B.: Automated cloud screening algorithm for MFRSR data, Geophys. Res. Lett., 31, L04118, doi:10.1029/2003GL019105, 2004.

Andrews, E., Sheridan, P., Ogren, J., and Ferrare, R.: In situ aerosol profiles over the Southern Great Plains cloud and radiation test bed site: 1. Aerosol optical properties, J. Geophys. Res., 109, D06208, doi:10.1029/2003JD004025, 2004

Berg, L. K. and Stull, R. B.: Accuracy of point and line measures of boundary layer cloud amount, J. Appl. Meteorol., 41, 640-650, 2002.

Brown, A., Cederwall, R. T., Chlond, A., et al.: Large-eddy simulation of the diurnal cycle of shallow cumulus convection over land, Q. J. R. Meteorol. Soc., 128, 1075-1093, 2002.

Clothiaux, E., Ackerman, T. P., Mace, G. G., et al.: Objective determination of cloud heights and radar reflectivities using a combination of active remote sensors at the ARM CART sites, J. Appl. Meteorol., 39, 645-665, 2000.

Delene, D. and Ogren, J.: Variability of aerosol optical properties at four north American surface monitoring sites, J. Atmos. Sci., 15, 1135-1150, 2002.

25 Dong, X., Xi, B., and Minnis, P.: A climatology of midlatitude continental clouds from the ARM SGP Central Facility. Part II: Cloud fraction and surface radiative forcing, J. Climate, 19, 1765-1783, 2006.

Fan, J., Zhang, R., Li, G., Tao, W.-K., and Li, X.: Simulation of cumulus clouds using a spectral microphysics cloud-resolving model, J. Geophys. Res., 112, D04201, doi:10.1029/2006JD007688, 2007.

\section{Relationships between aerosol optical depth and cumulus fraction}

E. I. Kassianov et al.

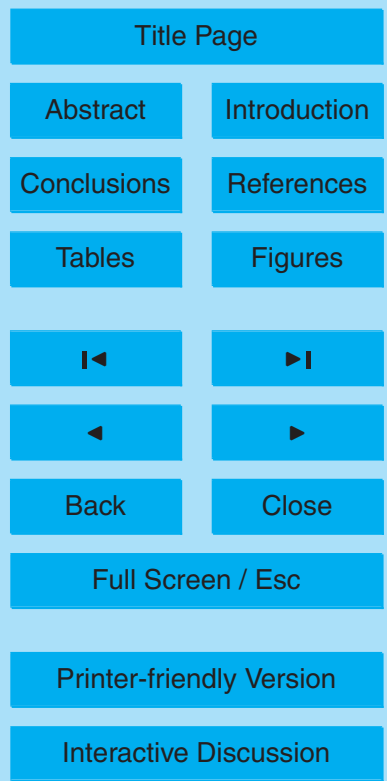


Feingold, G., Jiang, H., and Harrington, J. Y.: On smoke suppression of clouds in Amazonia, Geophys. Res. Lett., 32, L02804, doi:10.1029/2004GL021369, 2005.

Ferrare, R., Turner, D., Clayton, M., et al.: Evaluation of daytime measurements of aerosols and water vapor made by an operational Raman lidar over the Southern Great Plains, J. Geophys. Res., 111, D05S08, doi:10.1029/2005JD005836, 2006.

Guo, H., Penner, J., Herzog, M., and Pawlowska, H.: Examination of the aerosol indirect effect under contrasting environments during the ACE-2 experiment, Atmos. Chem. Phys., 7, 535548, 2007.

Hansen, J. E., Sato, M., and Ruedy, R.: Radiative forcing and climate response, J. Geophys. Res., 102, 6831-6864, 1997.

Harrison, L. and Michalsky, J.: Objective algorithms for the retrieval of optical depths from ground-based measurements, J. Appl. Opt., 22, 5126-5132, 1994.

Jiang, H. and Feingold, G.: Effect of aerosol on warm convective clouds: Aerosol-cloudsurface flux feedbacks in a new coupled large eddy model, J. Geophys. Res., 111, doi:10.1029/2005JD006138, 2006.

Jiang, H., Xue, H., Teller, A., Feingold, G., and Levin, Z.: Aerosol effects on the lifetime of shallow cumulus, Geophys. Res. Lett., 33, L14806, doi:10.1029/2006GL026024, 2006.

Johnson, B. T., Shine, K. P., and Forster, P. M.: The semi-direct aerosol effect: Impact of absorbing aerosols on marine stratocumulus, Q. J. R. Meteorol. Soc., 30, 1407-1422, 2004.

20 Kassianov, E. I., Long, C. N., and Ovtchinnikov, M.: Cloud sky cover versus cloud fraction: Whole-sky simulations and observations, J. Appl. Meteorol., 44, 86-98, 2005a.

Kassianov, E. I., Ackerman, T. P., and Kollias, P.: The role of cloud-scale resolution on radiative properties of oceanic cumulus clouds, J. Quant. Spectrosc. Radiat. Transfer., 91, 211-226, 2005b.

Kato, S., Hinkelman, L., and Cheng, A.: Estimate of satellite-derived cloud optical thickness and effective radius errors and their effect on computed domain-averaged irradiances, $\mathrm{J}$. Geophys. Res., 111, D17201, doi:10.1029/2005JD006668, 2006.

Kaufman, Y. and Koren, I.: Smoke and pollution aerosol effect on cloud cover, Science, 313, 3271-3274, 2006.

so Kaufman, Y., Koren, I., Y., Remer, L., Rosenfeld, D., and Rudich, Y.: Effect of smoke, dust, and pollution aerosol on shallow cloud development over the Atlantic Ocean, Proc. Natl. Acad. Sci., 102, 11 207-11212, 2005.

Koren, I., Kaufman, Y. J., Rosenfeld, D., and Remer, L.: Aerosol invigoration and restructuring

\section{Relationships between aerosol optical depth and cumulus fraction}

E. I. Kassianov et al.

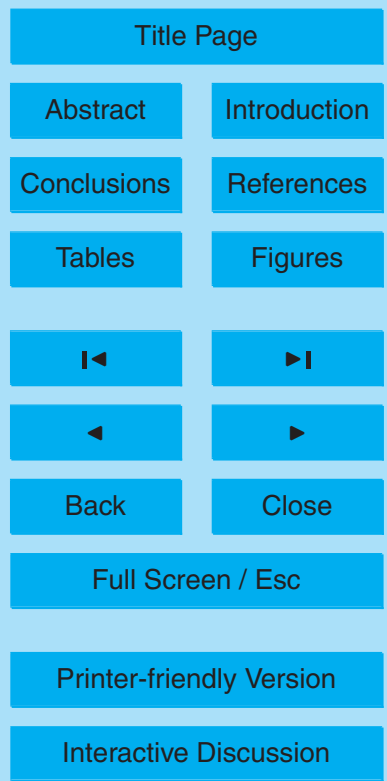


of Atlantic convective clouds, Geophys. Res. Lett., 32, L14828, doi:10.1029/2005GL023187, 2005.

Lohmann, U. and Feichter, J.: Global indirect aerosol effects: A review, J. Atmos. Chem. Phys., 5, 715-737, 2005.

5 Lohmann, U., Koren, I., and Kaufman, Y.: Disentangling the role of microphysical and dynamical effects in determining cloud properties over the Atlantic, Geophys. Res. Lett., 33, L09802, doi:10.1029/2005GL024625, 2006.

McCarthy, J.: Field verification of the relationship between entrainment rate and cumulus cloud diameter, J. Atmos. Sci., 31, 1028-1039, 1974.

10 McFarquhar, G., Platnick, S., Di Girolamo, L., Wang, H., Wind, G., and Zhao, G.: Trade wind cumuli statistics in clean and polluted air over the Indian Ocean from in situ and remote sensing measurements, Geophys. Res. Lett., 31, L21105, doi:10.1029/2004GL020412, 2004.

Michalsky, J. J., Schlemmer, J. A., Berkheiser, W. E., et al.: Multiyear measurements of aerosol optical depth in the Atmospheric Radiation Measurement and Quantitative Links programs,

15 J. Geophys. Res., 106, 12 099-12 107, 2001.

Mitchell, R., O'Brien, D., and Campbell, S.: Characteristics and radiative impact of the aerosol generated by the Canberra firestorm of January 2003, J. Geophys. Res., 111, D02204, doi:10.1029/2005JD006304, 2006.

Norris, J. R.: Has northern Indian Ocean cloud cover changed due to increasing anthropogenic aerosol?, J. Geophys. Res. Lett., 28, 3271-3274, 2001.

Rodts, S. M. A., Duynkerke, P. G., and Jonker, H. J. J.: Size distributions and dynamical properties of shallow cumulus clouds from aircraft observations and satellite data, J. Atmos. Sci., 60, 1895-1912, 2003.

Sekiguchi, M., Nakajima, T., Suzuki, K., Kawamoto, K., Higurashi, A., Rosenfeld, D., Sano, I., and Mukai, S.: A study of the direct and indirect effects of aerosol using global satellite data sets of aerosol and cloud parameters, J. Geophys. Res., 108, doi:10.1029/2002JD003359, 2003.

Sheridan, P., Delene, D., and Ogren, J.: Four years of continuous surface aerosol measurements from the Department of Energy's Atmospheric Radiation Measurement Program

30 Southern Great Plains Cloud and Radiation Testbed site, J. Geophys. Res., 106, 20735 20747, 2001.

Stephens, G.: Remote Sensing of the Lower Atmosphere, Oxford University Press, 523 pp, 1994.

\section{Relationships between aerosol optical depth and cumulus fraction}

E. I. Kassianov et al.

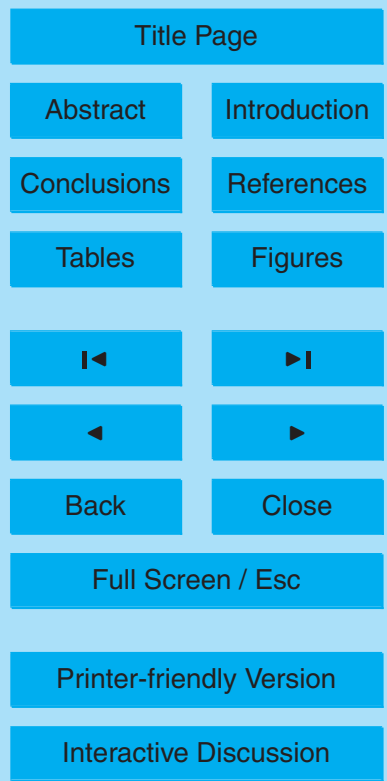


Stokes, G. M. and Schwartz, S. E.: The Atmospheric Radiation Measurement (ARM) Program: Programmatic background and design of the Cloud and Radiation Test Bed, Bull. Am. Meteorol. Soc., 75, 1201-1221, 1994.

Turner, D. D.: Arctic mixed-phase cloud properties from AERI-lidar observations: Algorithm and results from SHEBA, J. Appl. Meteorol., 44, 427-444, 2005.

Turner, D. D., Vogelmann, A. M., Austin, R. T., et al.: Thin liquid water clouds: Their importance and our challenge, Bull. Am. Meteorol. Soc., 88, 177-190, 2007.

Twomey, S.: The influence of pollution on the shortwave albedo of clouds, J. Atmos. Sci., 34, 1149-1152, 1977.

10 Vant-Hull, B., Marshak, A., Remer, L., and Li, Z.: The effects of scattering angle and cumulus cloud geometry on satellite retrievals of cloud droplet effective radius, IEEE Geo. Rem. Sens. Lett., 45, 1039-1045, 2007.

Warren, S. G., Eastman, R. M., and Haln, C. J.: A survey of changes in cloud cover and cloud types over land from surface observations, 1971-1996, J. Climate, 15, 717-738, 2007.

Xu, K., Zhang, M., Eitzen, Z. A., et al.: Modeling springtime shallow frontal clouds with cloud-resolving and single-column models, J. Geophys. Res., 110, D15S04, doi:10.1029/2004JD005153, 2005.

Xue, H. and Feingold, G.: Large-Eddy simulations of trade wind cumuli: Investigation of aerosol indirect effects, J. Atmos. Sci., 63, 1605-1622, 2006.

$20 \mathrm{Yu}, \mathrm{H}$., Liu, S., and Dickinson, R.: Radiative effects of aerosols on the evolution of the atmospheric boundary layer, J. Geophys. Res., 107, doi:10.1029/2001JD000754, 2002.

Zhao, M. and Austin, P.: Life cycle of numerically simulated shallow cumulus clouds. Part I: Transport, J. Atmos. Sci., 62, 1269-1290, 2005.

\section{ACPD}

7, 11797-11837, 2007

\section{Relationships between aerosol optical depth and cumulus fraction}

E. I. Kassianov et al.

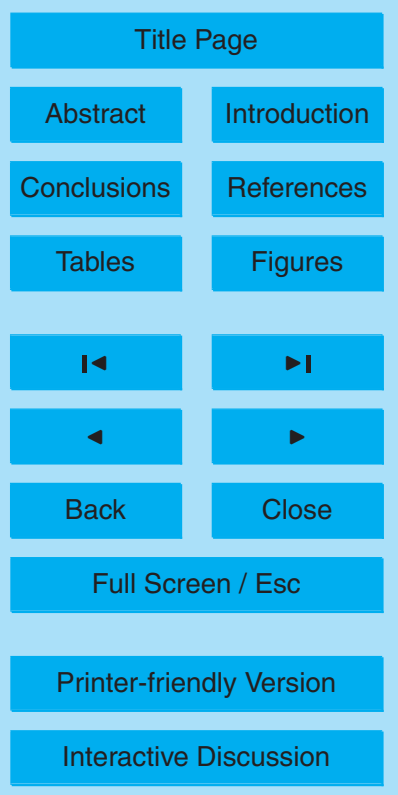




\section{ACPD}

7, 11797-11837, 2007

\section{Relationships between aerosol optical depth and cumulus fraction}

Table 1a. Fitting statistics for the linear regressions (CF versus AOD) as function of time day (Figs. 9, 10): the intercept, slope, correlation coefficient, and $p$ value for the $t$-test of the slope equals to 0 . These regressions are constructed by using seven points (bins).

\begin{tabular}{lllll}
\hline Case Description & Intercept & Slope & Correlation coefficient & $p$ value \\
\hline Morning (before 20:00 UTC) & 0.29 & 0.10 & 0.41 & 0.36 \\
Afternoon (after 20:00 UTC) & 0.31 & -0.13 & -0.83 & 0.04 \\
Large clouds $(>1 \mathrm{~km})$ & 0.36 & -0.06 & -0.42 & 0.35 \\
Small clouds $(\leq 1 \mathrm{~km})$ & 0.15 & 0.14 & 0.67 & 0.10
\end{tabular}

E. I. Kassianov et al.

Title Page

Abstract

Conclusions

Tables

References

Figures

14

4

Back

Full Screen / Esc

Printer-friendly Version

Interactive Discussion 


\section{ACPD}

7, 11797-11837, 2007

\section{Relationships between aerosol optical depth and cumulus fraction}

Table 1b. The same as Table 1a, except that these regressions are constructed by using six points (bins); the first point in Figs. 9 and 10 is ignored.

\begin{tabular}{lllll}
\hline Case Description & Intercept & Slope & Correlation coefficient & $p$ value \\
\hline Morning (before 20:00 UTC) & 0.35 & -0.03 & -0.15 & 0.77 \\
Afternoon (after 20:00 UTC) & 0.31 & -0.12 & -0.75 & 0.15 \\
Large clouds $(>1 \mathrm{~km})$ & 0.38 & -0.10 & -0.62 & 0.19 \\
Small clouds $(\leq 1 \mathrm{~km})$ & 0.16 & 0.12 & 0.52 & 0.29
\end{tabular}

E. I. Kassianov et al.

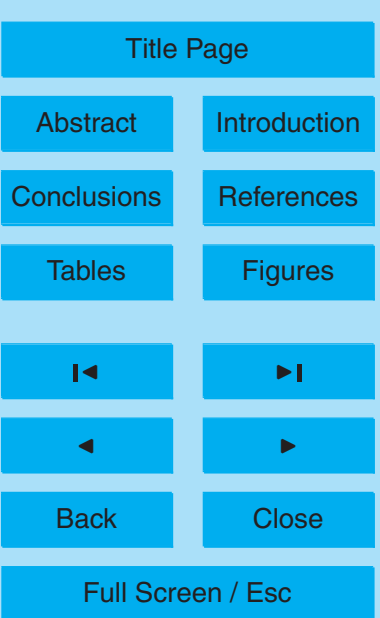

Printer-friendly Version

Interactive Discussion 


\section{ACPD}

7, 11797-11837, 2007

\section{Relationships between aerosol optical depth and cumulus fraction}

Table 2. The same as Table 1a, except that these regressions are constructed for the observed net broadband shortwave (SW) and longwave (LW) fluxes and their sum (SW+LW). The dimension of fluxes is $\mathrm{W} / \mathrm{m}^{2}$. The fluxes are observed in the morning (16:00-20:00 UTC), and in the afternoon (20:00-24:00 UTC).

\begin{tabular}{llllll}
\hline Time of day & Flux & Intercept & Slope & $\begin{array}{l}\text { Correlation } \\
\text { coefficient }\end{array}$ & $p$ value \\
\hline \multirow{3}{*}{ Morning } & SW & 697.4 & -26.4 & -0.23 & 0.62 \\
& LW & -103.6 & 35.3 & 0.69 & 0.09 \\
& SW+LW & 593.8 & 8.9 & 0.07 & 0.88 \\
\multirow{4}{*}{ Afternoon } & SW & 426.4 & 77.0 & 0.77 & 0.07 \\
& LW & -87.5 & 14.7 & 0.46 & 0.36 \\
& SW+LW & 338.8 & 91.7 & 0.79 & 0.06 \\
\hline
\end{tabular}

Title Page

Abstract

Conclusions
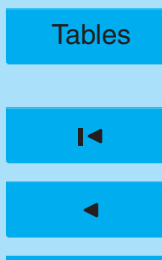

Back
Introduction

References

Figures

$>1$

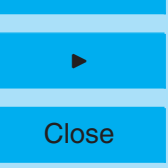

Full Screen / Esc

Printer-friendly Version 


\section{ACPD}

7, 11797-11837, 2007
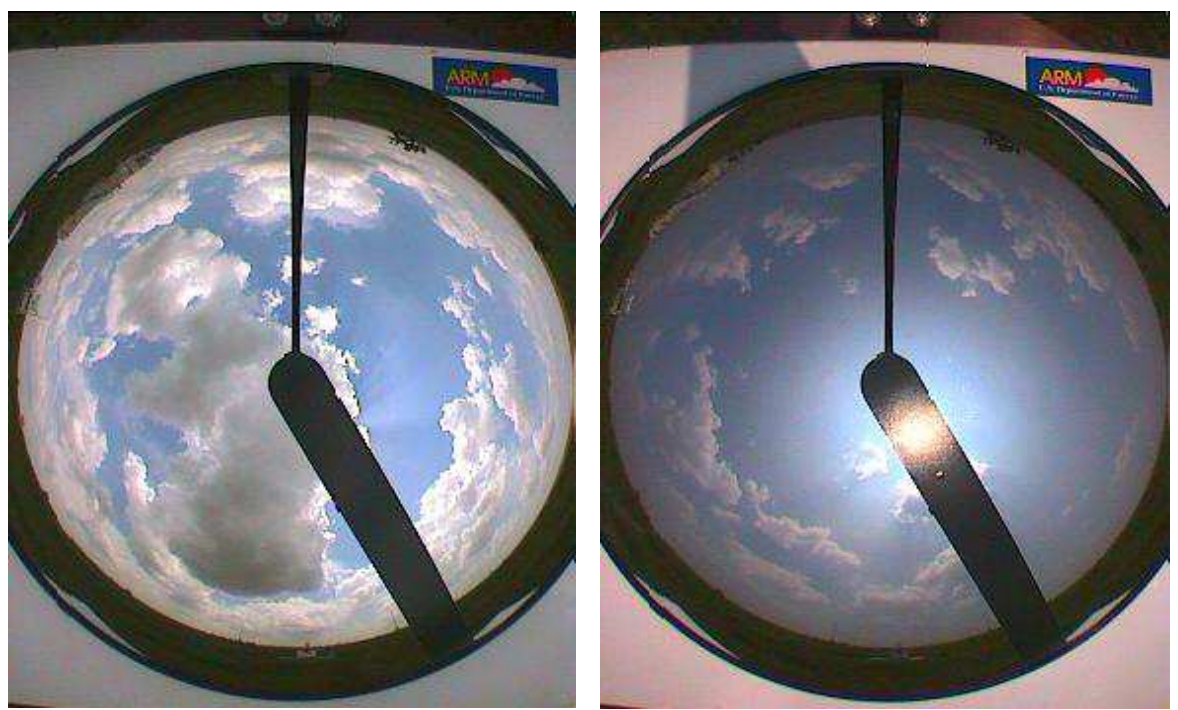

Relationships between aerosol optical depth and cumulus fraction

\section{E. I. Kassianov et al.}

Title Page

Abstract

Conclusions

Tables

14

4

Back

Full Screen / Esc

Printer-friendly Version 


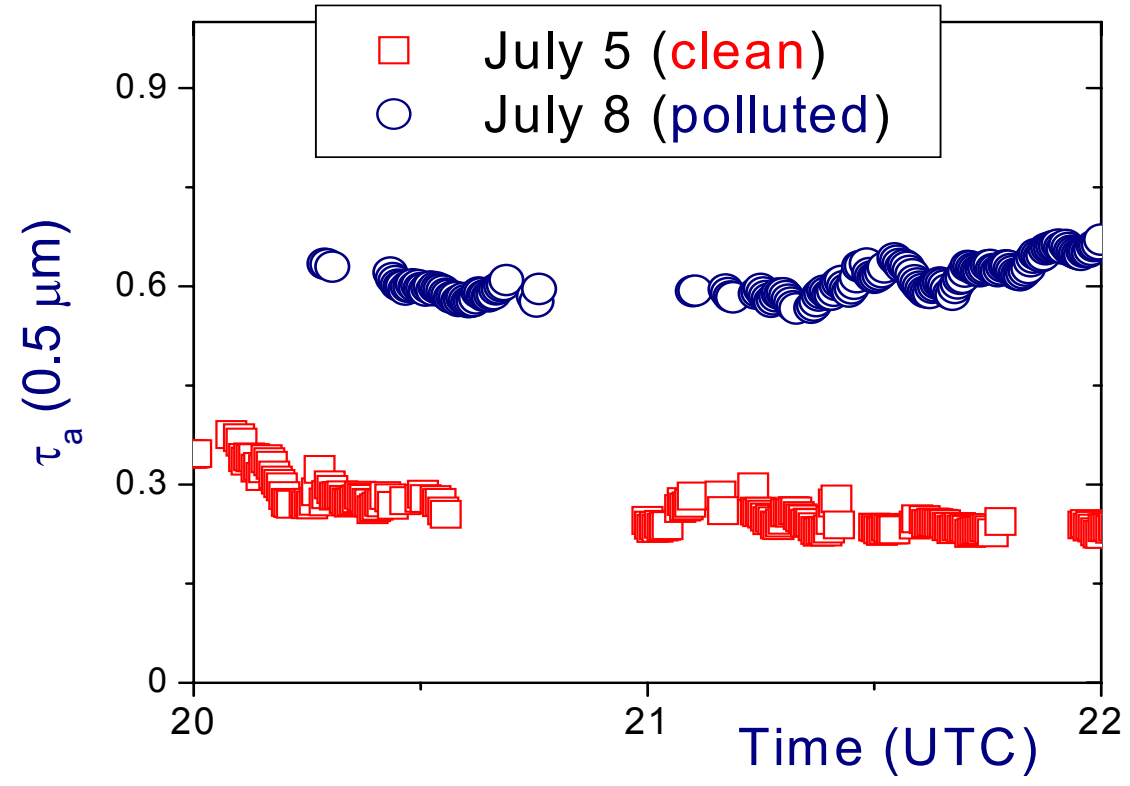

Fig. 2. The cloud screened MFRSR-derived aerosol optical depth $\tau_{a}$ obtained on 5 July 2002 (red), and 8 July 2002 (navy).
ACPD

7, 11797-11837, 2007

Relationships between aerosol optical depth and cumulus fraction

E. I. Kassianov et al.

Title Page

Abstract

Introduction

Conclusions

References

Tables

Figures

14

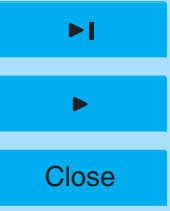

Back

Full Screen / Esc

Printer-friendly Version

Interactive Discussion 


\section{ACPD}

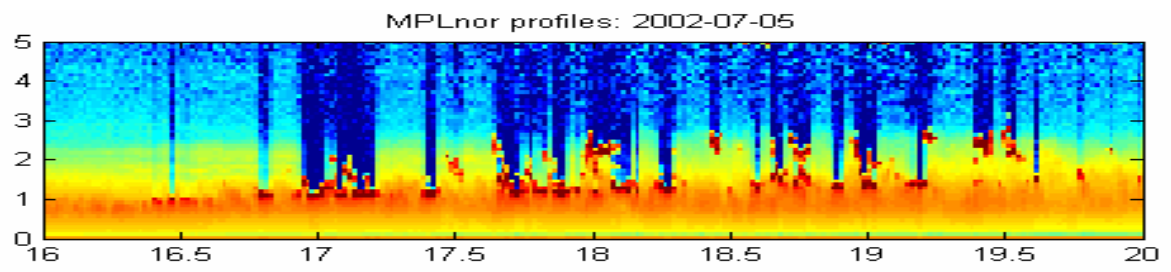

\section{Relationships between aerosol optical depth and cumulus fraction}

\section{E. I. Kassianov et al.}

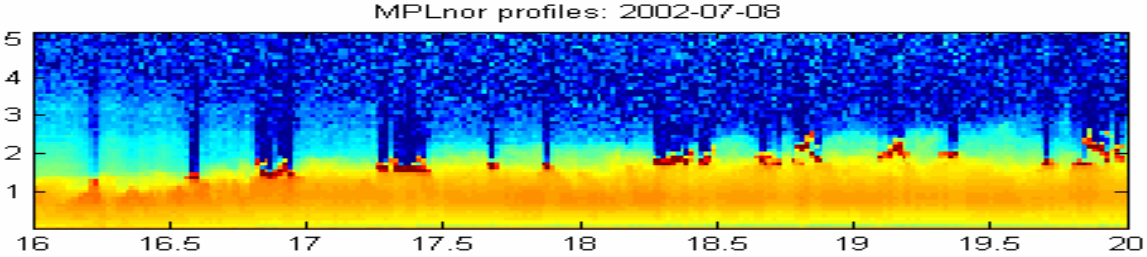

Title Page

\section{Abstract}

Conclusions

\section{Tables}

14

4

Back
Introduction

References

Figures

$\rightarrow$

$\rightarrow$

Close dots with dark red color are clouds. 


\section{ACPD}
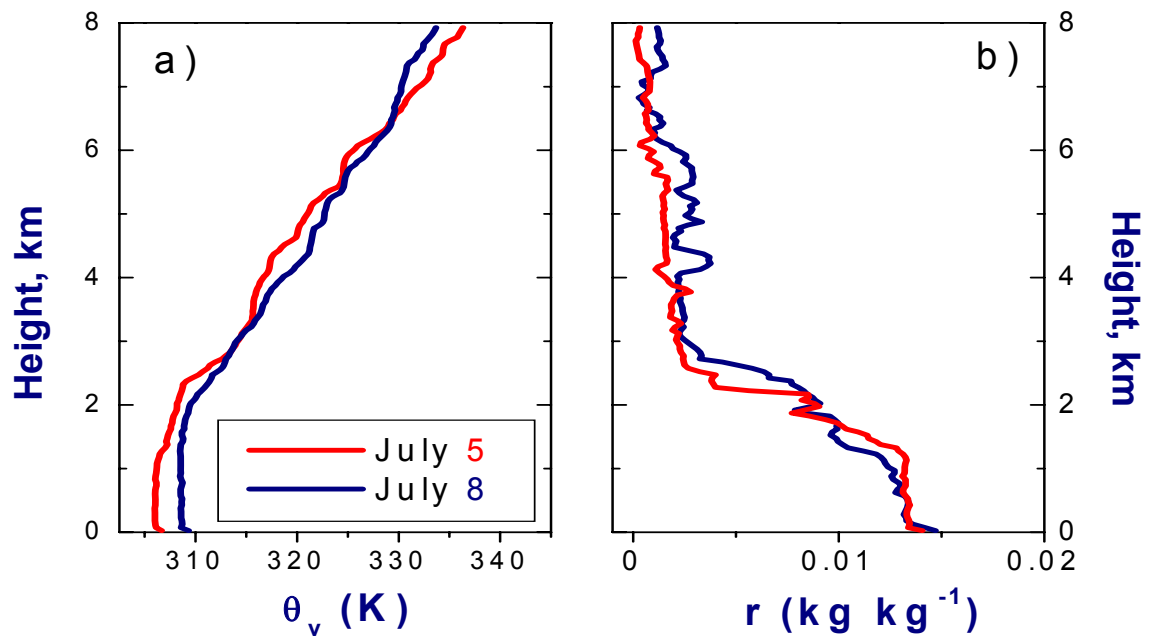

\section{Relationships between aerosol optical depth and cumulus fraction}

E. I. Kassianov et al.

Fig. 4. Vertical profiles of potential temperature (a) and mixing ratio (b) obtained on 5 July 2002 (red), and 8 July 2002 (navy).

Title Page

\section{Abstract}

Conclusions

Tables

References

Figures

14

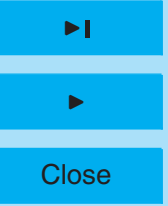

Full Screen / Esc

Printer-friendly Version 


\section{ACPD}

MODIS Cloud Phase ; Jul 5

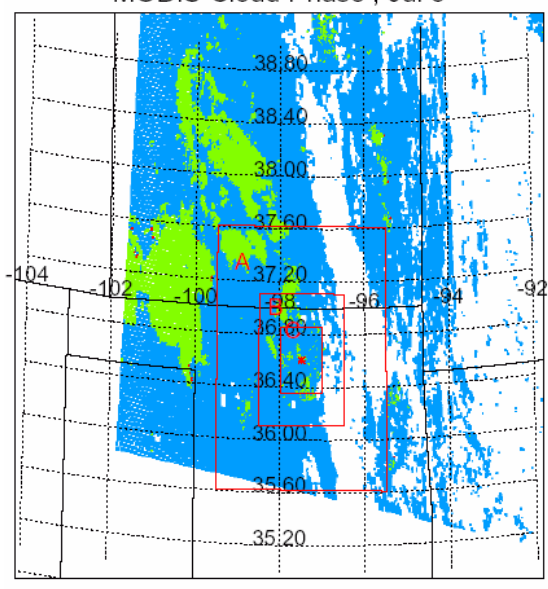

Cloud Phase

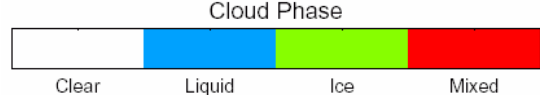

MODIS Cloud Phase ; Jul 8

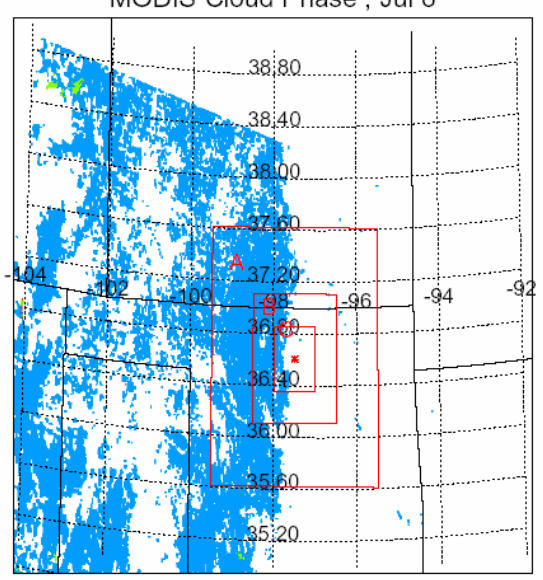

Cloud Phase

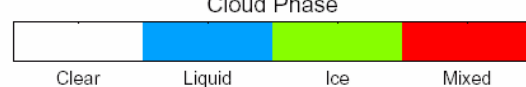

Fig. 5. The MODIS-derived cloud phase images obtained on 5 July 2002 (left), and 8 July 2002 (right). Blue and green colors represent liquid and ice clouds, respectively. The SGP site is represented by red star in the center of these images. Large, moderate and small areas surrounding the SGP site are labeled as A, B, and C, respectively.

\section{Relationships between aerosol optical depth and cumulus fraction}

E. I. Kassianov et al.

\section{Title Page}

\section{Abstract}

Conclusions

\section{Tables}

14

4

Back
Introduction

References

Figures

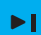

$>$

Close
Full Screen / Esc

Printer-friendly Version

Interactive Discussion 


\section{ACPD}
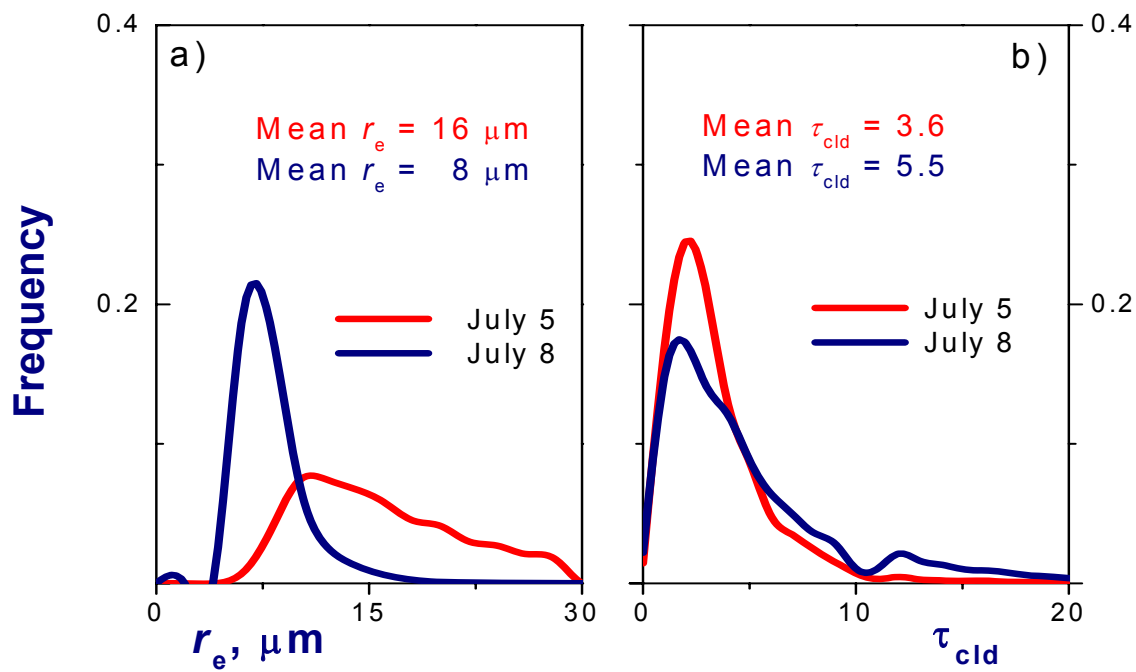

\section{Relationships between aerosol optical depth and cumulus fraction}

\section{E. I. Kassianov et al.}

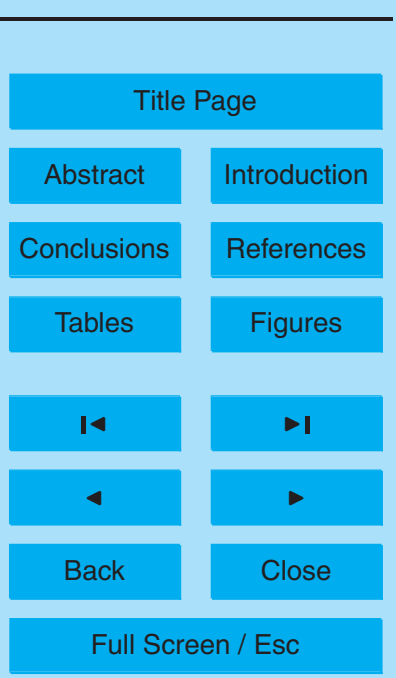

Fig. 6. Frequency distribution of (a) effective radius $r_{e}$ of droplets, (b) cloud optical depth $\tau_{\text {cld }}$ and the corresponding mean values estimated from the MODIS data for region A on 5 July 2002 (red), and 8 July 2002 (navy). 


\section{ACPD}

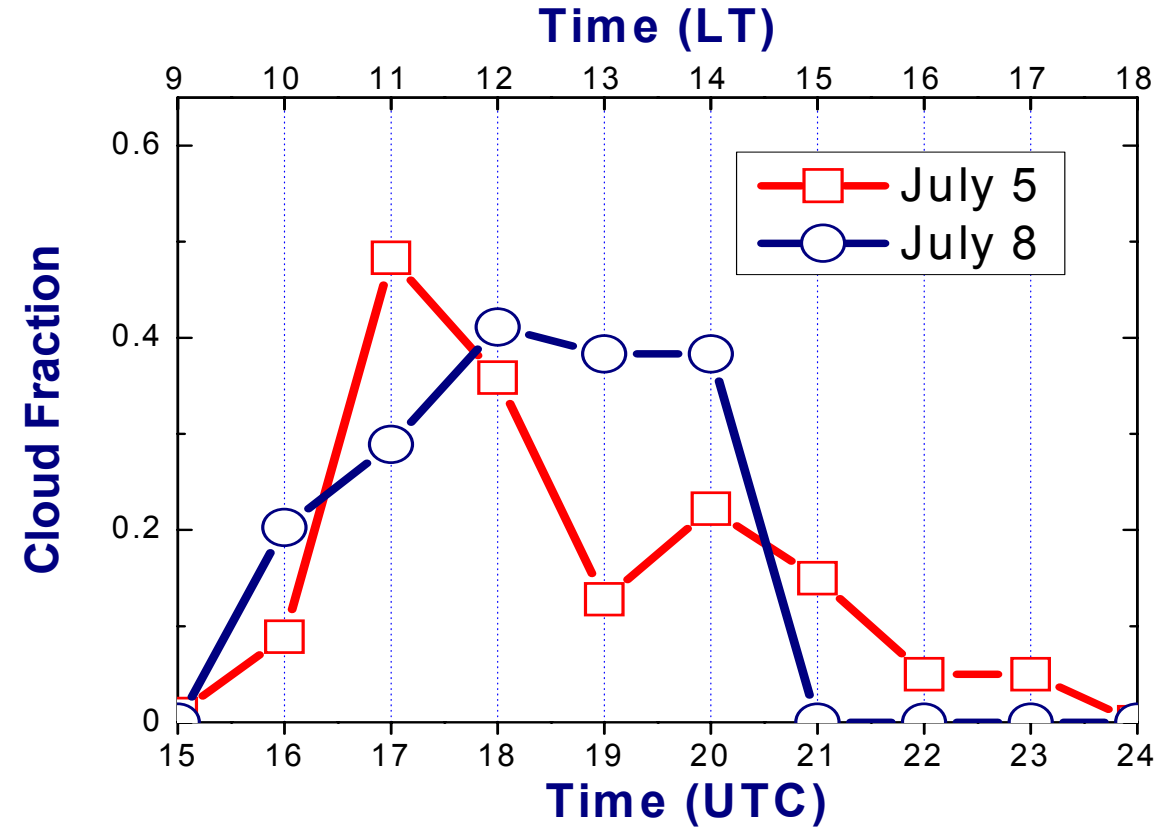

Fig. 7. Diurnal variability of the ARSCL-derived hourly averaged cloud fraction on July 5, 2002 (red), and July 8, 2002 (blue). Local Time (LT) is given at the top of Fig. 7.
Relationships between aerosol optical depth and cumulus fraction

E. I. Kassianov et al.

Title Page

Abstract

Introduction

Conclusions

References

Tables

Figures

14

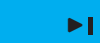

4

Back

Close

Full Screen / Esc

Printer-friendly Version

Interactive Discussion 


\section{ACPD}

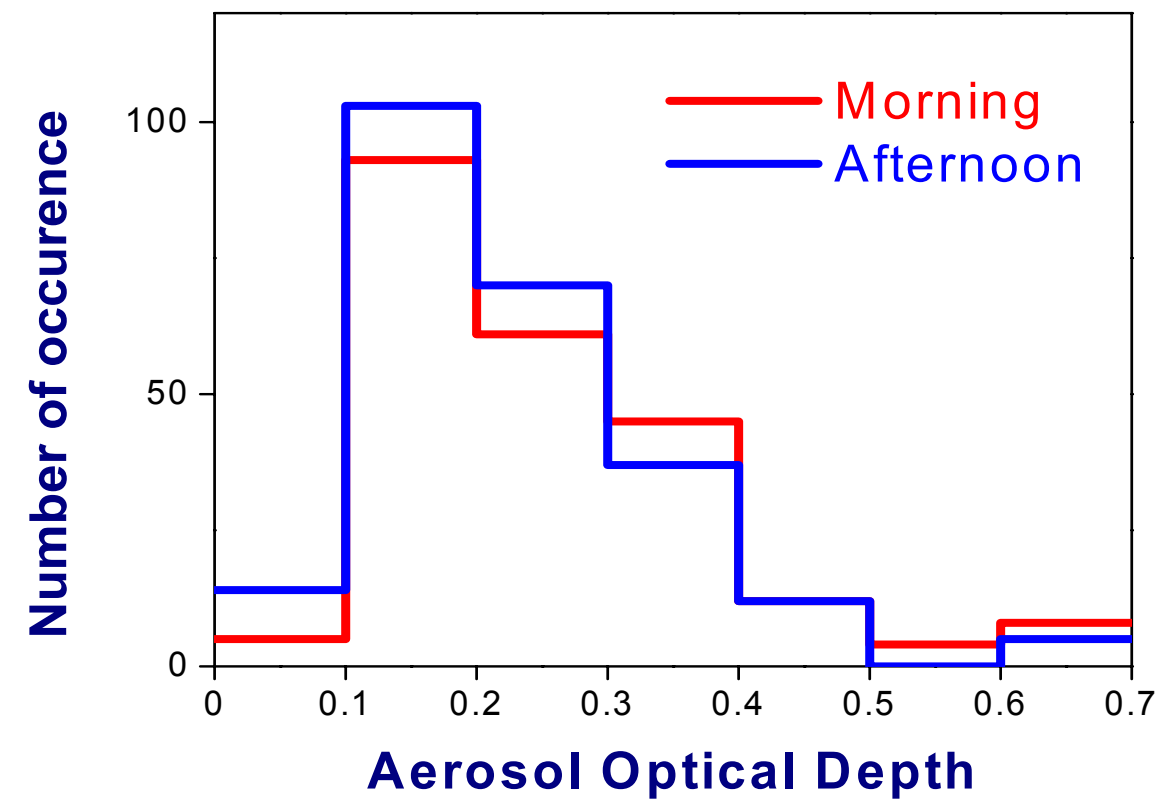

Fig. 8. Histograms of the number ARSCL-derived hourly averaged cloud fraction values in each aerosol optical depth bin for observations obtained in the morning (before 20:00 UTC) and in the afternoon (after 20:00 UTC). The morning histogram represents $226 \mathrm{~h}$ of data, while that for the afternoon represents $246 \mathrm{~h}$.

\section{Relationships between aerosol optical depth and cumulus fraction}

E. I. Kassianov et al.

Title Page

Abstract

Introduction

Conclusions

References

Tables

Figures

14

-1

4

Back

Close

Full Screen / Esc

Printer-friendly Version

Interactive Discussion 


\section{ACPD}

7, 11797-11837, 2007

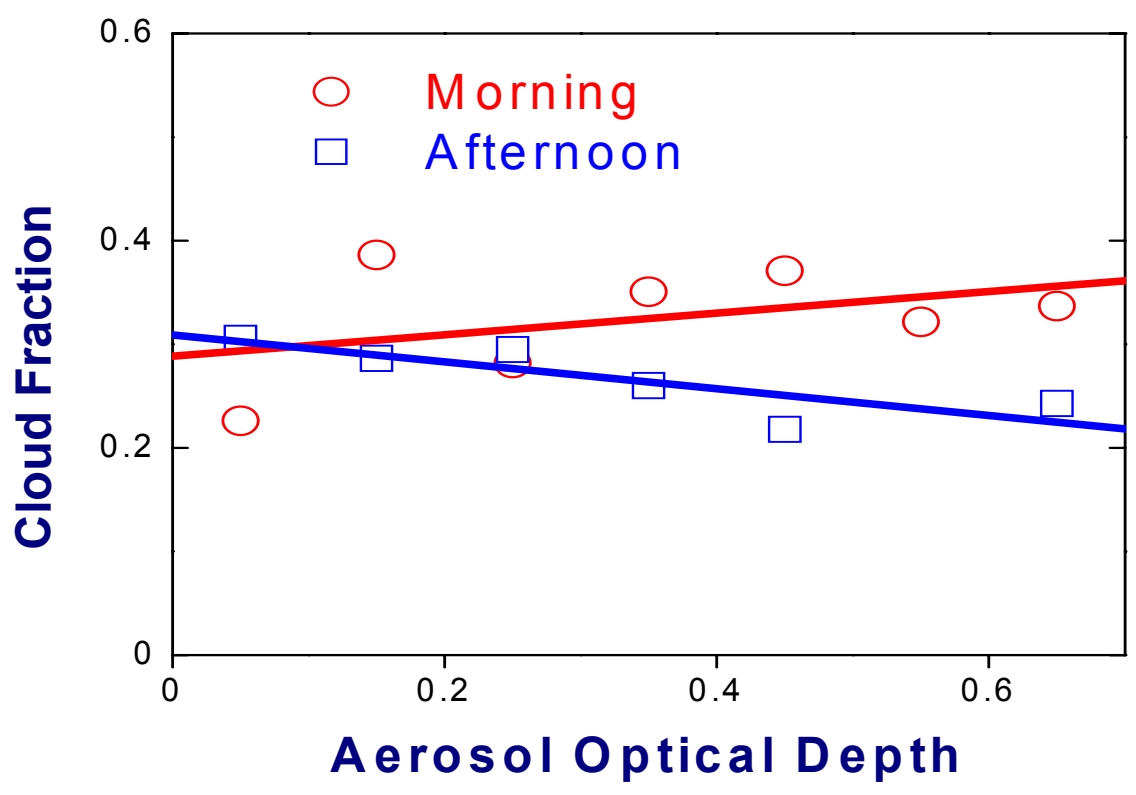

Fig. 9. Scatterplots and the corresponding linear regression lines as functions of time of day. Red and blue colors represent observations in the morning (before 20:00 UTC) and in the afternoon (after 20:00 UTC), respectively.

\section{Relationships between aerosol optical depth and cumulus fraction}

E. I. Kassianov et al.

Title Page

Abstract

Introduction

Conclusions

References

Tables

Figures

14

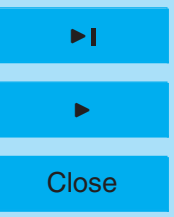

Back

Full Screen / Esc

Printer-friendly Version

Interactive Discussion 


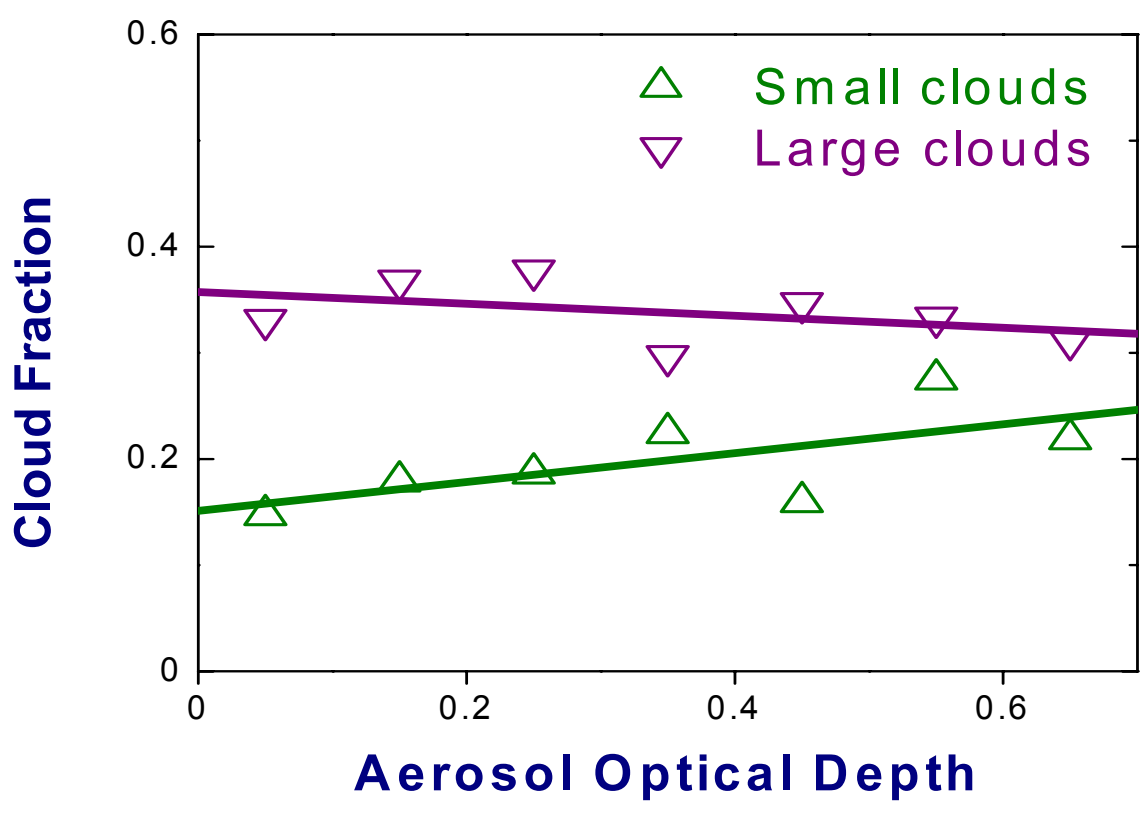

Fig. 10. Scatterplots and the corresponding linear regression lines as functions of mean horizontal cloud size $L$. Green and purple colors represent small $(\leq 1 \mathrm{~km})$ and large $(>1 \mathrm{~km})$ clouds, respectively.

\section{ACPD}

7, 11797-11837, 2007

Relationships between aerosol optical depth and cumulus fraction

E. I. Kassianov et al.

Title Page

Abstract

Introduction

Conclusions

References

Tables

Figures

14

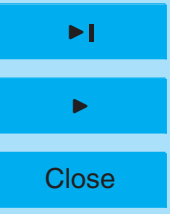

Back

Full Screen / Esc

Printer-friendly Version

Interactive Discussion 


\section{ACPD}
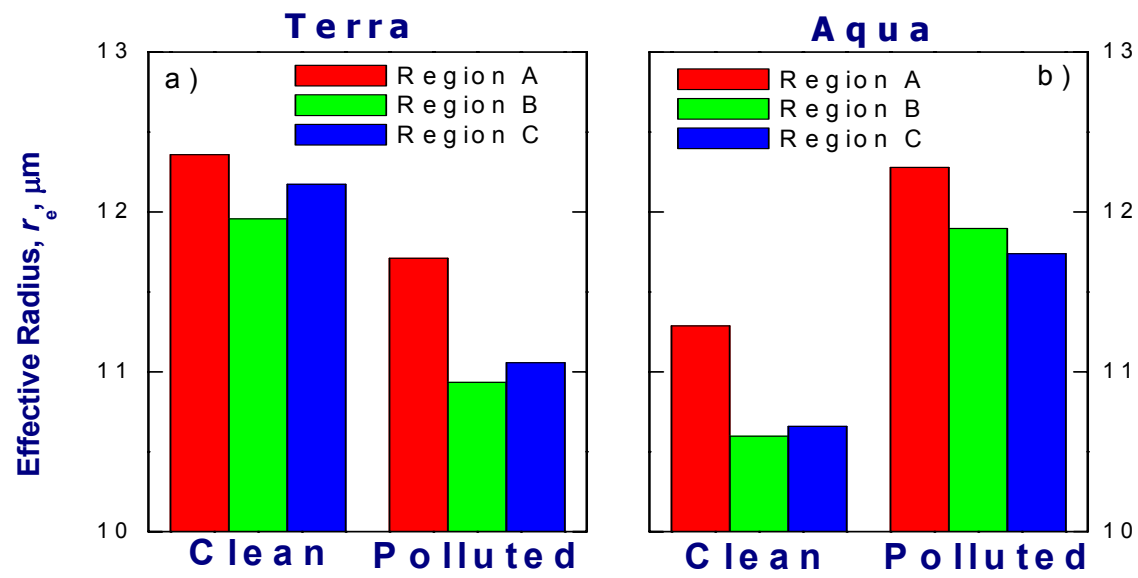

\section{Relationships between aerosol optical depth and cumulus fraction}

E. I. Kassianov et al.

Fig. 11. The liquid cloud effective radius $r_{e}$ obtained from the (a) Terra and (b) Aqua observations for three different regions. These regions represent large $(A)$, moderate $(B)$, and small $(C)$ areas surrounding the ACRF SGP site.

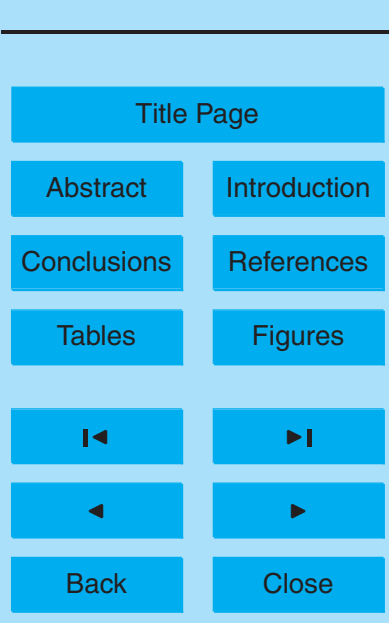

Full Screen / Esc

Printer-friendly Version

Interactive Discussion 


\section{ACPD}

7, 11797-11837, 2007
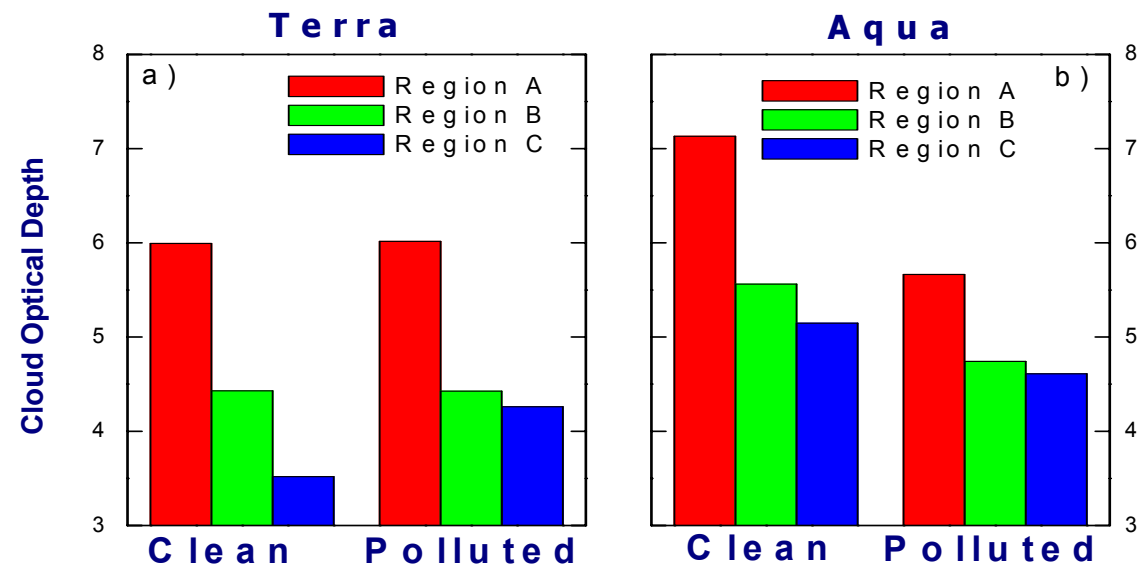

\section{Relationships between aerosol optical depth and cumulus fraction}

\section{E. I. Kassianov et al.}

Title Page

\section{Abstract}

Conclusions

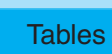

14

4

Back
Introduction

References

Figures

-1

Fig. 12. The same as in Fig. 11, except that these results correspond to the optical depth of liquid clouds.
Full Screen / Esc

Printer-friendly Version 